\title{
LES OUTILS À CUPULES, MARQUEURS DE LA MÉTALLURGIE DU DISTRICT DE CABRIÈRES-PÉRET (HÉRAULT) AU CHALCOLITHIQUE
}

\author{
Caroline HAMON ${ }^{1}$, Paul AmberT ${ }^{2}$, Marie LAROCHE ${ }^{3}$, Jean-Louis GUENDON ${ }^{4}$, \\ Salvador ROVIRA ${ }^{5}$ et Laurence BOUQUET ${ }^{6}$
}

\begin{abstract}
Mots-clés. Sud de la France, district de Cabrières, chalcolithique, métallurgie du cuivre, outillage en pierre, typologie, technologie, tracéologie.

Résumé. Les outils à cupules en provenance des aires de métallurgistes chalcolithiques du district minier de Cabrières-Péret dépassent désormais 150 exemplaires. L'étude de 116 de ces objets nous a permis de définir leur composition pétrographique, de procéder à leur classification en plusieurs morphotypes et de caractériser les traces plurielles de leur utilisation dans un contexte minier-métallurgique. Les cupules résulteraient d'un geste de concassage violent sur une matière dure et contondante: elles auraient donc servi à fracturer, voire réduire, les gros morceaux de matière en fragments de plus petites dimensions. La tranche et la face principale semblent plutôt destinées à réduire la matière en petites fractions, respectivement par une fine percussion et par un broyage en percussion posée circulaire. Cette action a pu être complétée dans certains cas par une percussion plus précise et plus fine à l'aide de l'extrémité des outils. L'analyse de la nature et de la répartition des traces d'utilisation sur les différentes faces de ces outils à cupules indique une transformation de matière minérale dure et plus particulièrement le broyage de fines particules minérales. Des traces ponctuelles d'oxydes de cuivre au niveau d'une des cupules soulignent qu'elles étaient le siège de chocs violents destinés à l'éclatement de roches minérales ou de produits métallurgiques durs et de petites tailles. La chauffe qui affecte la plupart des faces de ces pièces nous a fait préférer le second terme de cette alternative.

La présence de ces objets, parfois en grand nombre sur les principaux sites métallurgiques français (Saint-Véran, Hautes-Alpes), autrichiens (Brixlegg) et espagnols (Cabézo Juré), ne se dément pas dans le Proche- et le Moyen-Orient, soulignant bien leur rôle déterminant dans cette première métallurgie. Néanmoins, il semble que les caractéristiques techniques de ces artéfacts soient partagées par d'autres contextes et périodes chronologiques où les opérations de concassage tiennent une place importante notamment dans le domaine alimentaire pour le concassage des noix à coque très dure. Présents au Paléolithique (Isturitz, Pyrénées-Atlantiques) comme au Mésolithique, ils ont été également répertoriés dans des milieux récents par les ethnologues.
\end{abstract}

\footnotetext{
1. UMR 7041 ArScAn-Protohistoire européenne, Maison de l'archéologie et de l'ethnologie, 21, allée de l’Université, F-92023 Nanterre Cedex. Courriel: caroline.hamon@mae.u-paris10.fr

2. Université de Toulouse-Mirail, UMR 5608 du CNRS TRACES CRPPM, 39, allées Jules-Guesde, F-31080 Toulouse Cedex. Courriel: m.p.ambert@ wanadoo.fr

3. UMR 5608 du CNRS TRACES CRPPM - EHESS, 39, allées Jules-Guesde, F-31080 Toulouse Cedex. Courriel: marielaroche@wanadoo.fr 4. Université de Provence, UMR 6636 LAMPEA, Maison méditerranéenne des sciences de l'homme, BP 647, 5, rue du Château-de-l'Horloge, F-13094, Aix-en-Provence Cedex 2. Courriel: guendon@mmsh.univ-aix.fr

5. Museo arqueológico nacional, Serrano 13, Madrid, E-28001. Courriel: salvador.rovira@MCU.ES

6. CNRS FRE 2454, Proche-Orient, Caucase, Iran: Diversités et continuités, 52, rue du Cardinal-Lemoine, F-75005 Paris.
} 
Key-words. Southern France, Cabrières district, Chalcolithic, copper metallurgy, stone tools, typology, technology, use-wear analysis. Abstract. The stone crushing tools recovered from the Chalcolithic metallurgical zones of the mining district of Cabrières-Peret currently exceed 150 items. The study of 116 of these objects allows us to define their petrographical composition, to classify them into several types and to characterize the multiple traces of their function in mining and metallurgical contexts.

The crushing tools appear to be the result of an act of violent crushing on a blunt and hard material: they would have served to break, or even crush, big fragments of material into smaller dimensions. The edge and principal face seem to have been used to reduce the material into small fractions, both by fine percussion and by grinding-percussion with a circular movement. These actions could have been completed in some cases by a more precise and fine percussion using the extremities of the tools.

Analyses of the nature and distribution of use-wear traces on the different surfaces of these stone crushing tools indicate a transformation of a hard mineral material and particularly the grinding of fine mineral particles. Scattered traces of copper oxides in one of the crushing tools indicate that they were subject to violent impacts intended to break mineral rocks or hard but small metallurgical products. The heat that affected most of the faces of these tools leads us to favour the second alternative.

The sometimes abundant presence of these objects in the most important metallurgical sites in France (Saint-Véran, Hautes-Alpes), Austria (Brixlegg), and Spain (Vabezo Juré), without forgetting the Near and Middle Orient sites, emphasizes their determinant role in this metallurgy. Nevertheless, it seems that the technical characteristics of these artefacts are shared by other contexts and chronological periods in which grinding operations played an important role, for example for the crushing of hard nuts. They are present not only in the Palaeolithic (Isturitz, Pyrénées-Atlantiques) and Mesolithic, but have also been recorded by ethnologists in more recent contexts.

Schlüsselwörter. Südfrankreich, Grubendistrikt Cabrières, Chalkolithikum, Kupferverarbeitung, Steingeräte, Typologie, Technologie, Gebrauchsspurenanalyse.

Zusammenfassung. Die Geräte mit Grübchen ("galets à cupules») aus den Bereichen der Kupferverarbeitung des Grubendistrikts von Cabrières-Péret übersteigen fortan 150 Exemplare. Die Untersuchung 116 dieser Gegenstände hat es uns ermöglicht, ihre petrographische Komposition zu definieren, sie nach morphologischen Kriterien in mehrere Typen zu untergliedern und ihre Gebrauchsspuren im Kontext des Metallbergbaus zu untersuchen.

Die Grübchen wären auf eine heftige Geste bei der Zerkleinerung eines harten und stumpfen Materials zurückzuführen: sie hätten also dazu gedient, dickere Materialbrocken in kleinere Stücke zu brechen oder gar zu zerstoßen. Die Profil- und die Oberfläche scheinen eher dazu gedient zu haben, das Material durch präzises Zerstoßen bzw. durch Zermahlen mit kreisenden Klopfbewegungen in kleinere Stücke zu reduzieren. Diese Aktion kann in bestimmten Fällen durch gezielteres und feineres Zerstoßen mittels der Extremität des Geräts ergänzt werden.

Die Analyse der Art und der Verteilung der Gebrauchsspuren auf den unterschiedlichen Seiten dieser Geräte mit Grübchen weist auf die Verarbeitung eines harten mineralischen Gesteins insbesondere auf das Zerstoßen feiner mineralischer Partikel. Die Spuren von Kupferoxyden im Bereich eines der Grübchen unterstreichen die Tatsache, dass sie heftigen Schlägen ausgesetzt waren, die der Spaltung mineralischen Gesteins oder harter und kleiner Metallprodukte dienten. Die Spuren von Hitzeeinwirkung an den meisten Seiten dieser Stücke haben uns bewogen, die zweite der beiden Alternativen zu bevorzugen.

Das Vorhandensein solcher Gegenstände, manchmal in großer Anzahl auf den wichtigsten französischen (Saint-Véran, Departement Hautes-Alpes), österreichischen (Brixlegg) und spanischen (Cabézo Juré) Stätten der Metallverarbeitung wird auch im Vorderen und Mittleren Osten nicht dementiert und unterstreicht so ihre entscheidende Rolle in der frühen Metallverarbeitung. Gleichwohl scheint es, dass die technologischen Eigenschaften dieser Gegenstände mit anderen Kontexten und chronologischen Perioden geteilt werden, in denen das Zerstoßen eine wichtige Rolle spielt, insbesondere im Lebensmittelbereich, wo sie dem Brechen von Nüssen mit sehr harter Schale dienen. Sie sind sowohl im Paläolithikum (Isturitz) als auch im Mesolithikum vertreten und von den Ethnologen ebenfalls in jüngeren Kontexten registriert.

Übersetzung: Isa ODENHARDT-DONVEZ

\section{HISTORIQUE DES DÉCOUVERTES}

C'est en août 1980, lors du défoncement d'une parcelle de vigne ${ }^{1}$ au début de nos recherches dans le district minier-métallurgique chalcolithique de Cabrières-Péret,

1. B2 416 du cadastre de Cabrières. que nous avons été pour la première fois confrontés à l'objet que, faute de références, nous avons alors appelé «galets à cupules» (Ambert et al., 1984; Espérou, 1993). Depuis lors, les découvertes de pièces isolées ou celles réalisées dans les nouveaux sites métallurgiques mis au jour (Pioch-Farrus 448, la Capitelle du Broum, Valat Grand) (fig. 1) sont venues augmenter leur nombre qui dépasse très largement 


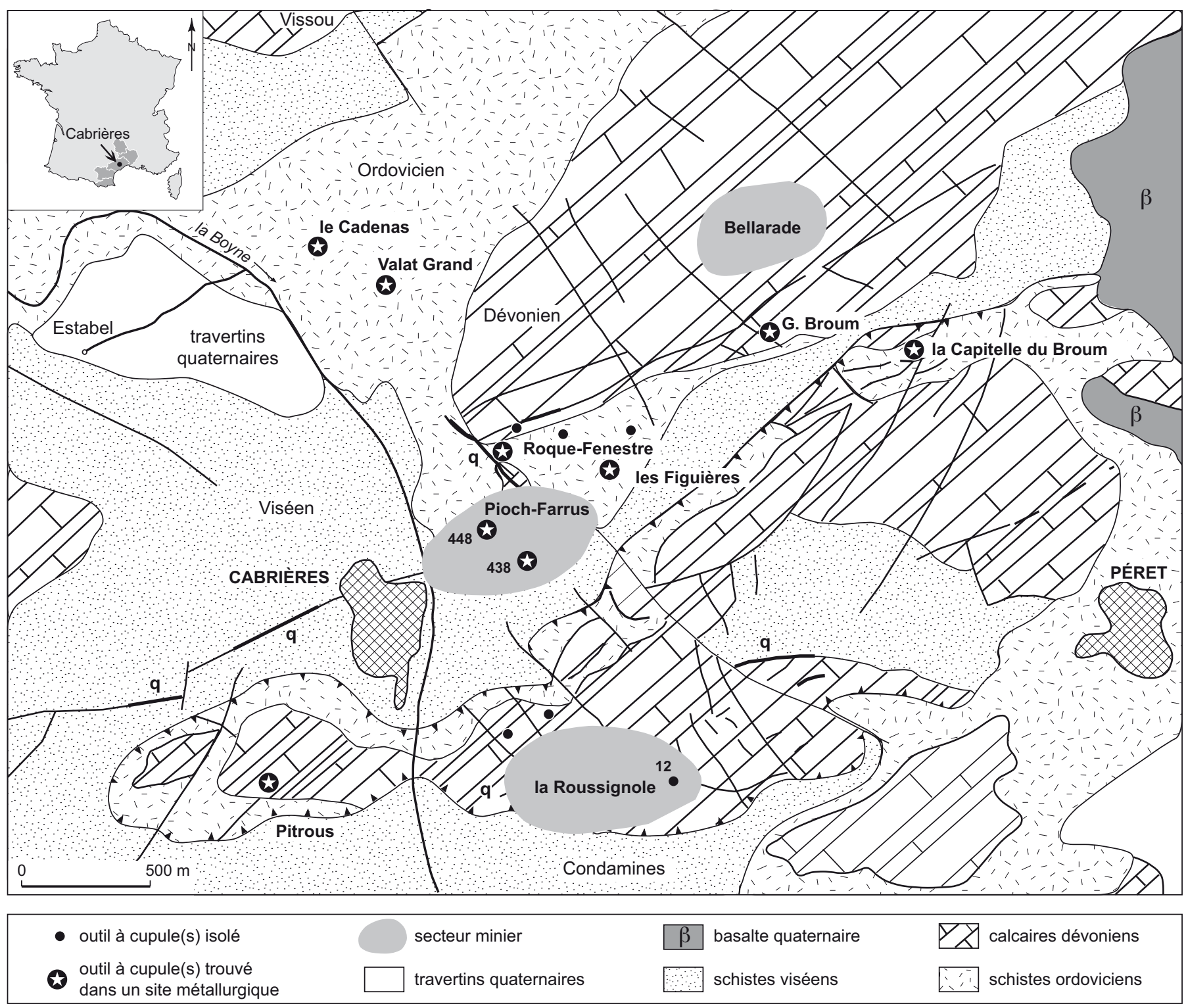

Fig. 1 - Carte de répartition des outils à cupules dans le district minier-métallurgique de Cabrières-Péret (Hérault) (DAO: C. Requirand).

la centaine dans le seul district minier-métallurgique de Cabrières-Péret.

Les « galets à cupules » se définissent initialement comme des outils présentant une cupule obtenue par percussion sur une ou plusieurs de leurs faces. Malgré des formes variées et un façonnage assez peu soigné, leurs dimensions sont relativement uniformes, avec des largeurs comprises entre $8 \mathrm{~cm}$ et $10 \mathrm{~cm}$ et des épaisseurs comprises entre $3 \mathrm{~cm}$ et $5 \mathrm{~cm}$.

Dès le début de nos recherches dans ce secteur, la richesse minérale et les quelques indices métallurgiques de Roque-Fenestre (scories, gouttes de cuivre) nous amenèrent à considérer ces galets comme spécifiques «du traitement et de la transformation du minerai en métal» (Ambert et al., 1985) puis, compte tenu de leur étroite relation avec les sites métallurgiques, «comme un outil de métallurgiste aux fonctions imprécises» (Espérou, 1988). Des travaux récents, plus spécifiques, ont permis d'en préciser la typologie (Cert, 2003 et 2005) puis d'en mener une première approche tracéologique (Hamon, 2006b).

Au bénéfice de l'étude d'un nombre représentatif de ces objets, nous avons souhaité dans cet article aller plus avant dans la compréhension de leur utilisation. C'est ainsi 
qu'au terme d'une approche typologique et tracéologique combinée avec une étude pétrographique, il est désormais possible de caractériser l'étendue de leurs fonctions, de préciser leur caractère opportuniste ou, au contraire, très élaboré.

\section{CONTEXTES DE DÉCOUVERTES ET ÉTUDE PÉTROGRAPHIQUE \\ LES SITES À OUTILS À CUPULES DU DISTRICT DE CABRIÈRES-PÉRET}

La répartition des sites ayant livré des outils à cupules est représentée dans la figure 1.

Les fosses de Roque-Fenestre, dont le mobilier a été publié (Ambert et al., 1984; Espérou, 1993) et largement divulgué dans des notes de synthèse afférentes au district métallurgique de Cabrières-Péret, sont les premières à avoir fourni des traces indubitables de métallurgie chalcolithique datée entre $4010 \pm 70 \mathrm{BP}(2900-2250$ cal. BC, Lv-1724) et $3870 \pm 80$ BP (2600-2050 cal. BC, Lv-1723). Ce site a livré in fine plus de 30 outils à cupules (fig. 2).

Plus récemment, au pied des calcaires du pic de Vissou, les travaux agricoles réalisés dans des schistes ordoviciens ont permis de mettre en évidence un groupe de fosses et de locus chalcolithiques, très démantelés (Laroche, 2004; Espérou, 2006; Ambert et al., 2006). Ces deux sites, dits du Cadenas et du Valat Grand, ont également fourni plus de 30 outils à cupules, découverts pour la plupart en prospection pédestre. Ici encore, plusieurs témoins métallurgiques (vase-four, concassages de scories, gouttes de cuivre) ont été mis au jour. Deux dates ${ }^{14} \mathrm{CAMS}$, contemporaines et associées à ces indices métallurgiques, ont été obtenues sur ce site. La dernière d'entre elles a donné $4060 \pm 35 \mathrm{BP}$ (Poz 21762), soit 2850-2810, 2750-2720 et 2700-2470 cal. BC.

Sur la commune de Cabrières, plusieurs sites non datés (Pioch-Farrus 438, Pitrous, les Figuières, Japhet) ont fourni un ou plusieurs outils à cupules. Il semble donc difficile de certifier que les deux sites qui ont fourni la majeure partie des galets à cupules (la Capitelle du Broum et RoqueFenestre) soient contemporains.

La fosse de Pioch-Farrus 448 (Espérou et al., 1994) associe des outils à cupules à des résidus (scories, gouttes, fragment de vase-four) d'une métallurgie vraisemblablement issue d'un minerai local, contenant pro parte de la chalcopyrite. La datation ${ }^{14} \mathrm{C}$ de $4310 \pm 75 \mathrm{BP}(\mathrm{Lv}-2039)$, soit 3350-2650 cal. BC, serait l'une des plus anciennes obtenues pour des pratiques métallurgiques dans ce district. Si cette dernière n'est pas incompatible avec le mobilier archéologique associé, il convient de rester prudent au sujet de cette datation haute car un effet «vieux bois» de l'échantillon de charbon analysé ne peut être complètement exclu.

Enfin, le village de métallurgistes de la Capitelle du Broum (Ambert et al., 2002, 2003 et 2005), dont les fouilles se poursuivent, a fourni au sein des couches de l'âge du Cuivre un riche échantillonnage d'outils à cupules (aujourd'hui la cinquantaine d'exemplaires est dépassée) (fig. 3). Tous les morphotypes y sont représentés ( $c f$. infra, p. 188). Plusieurs de ces pièces sont directement associées à des activités en lien avec la métallurgie et cela à plusieurs niveaux de l'occupation humaine chalcolithique, laquelle s'échelonnerait entre $4390 \pm 40 \mathrm{BP}$ (Beta 155559), soit 3120-2900 cal. BC, et $3799 \pm 27$ BP (Heidelberg cap 3), soit 2310-2130 cal. BC. Là aussi cependant, les plus anciennes dates (non confirmées par les nouvelles analyses) pourraient relever d'effets «vieux bois». Actuellement, en accord avec la stratigraphie, les dates de l'occupation chalcolithique se resserreraient entre $4100 \pm 35$ BP (2870-2490 cal. BC, Poz 18913) et 3950 \pm 40 BP (2580-2300 cal. BC, Beta 207259).

Malgré des recoupements chronologiques importants, il semble difficile, dans l'état actuel des recherches, de certifier que tous les sites qui ont fourni des galets à cupules soient strictement contemporains.

Quelques différences typologiques semblent apparaître dans l'outillage de deux sites principaux (tabl. I). Bien qu'elles reposent sur un faible nombre de pièces, ces différences pourraient être liées au type de structures dont ils proviennent. Il s'agit, dans le cas de Roque-Fenestre, de fosses de lavage-triage et, dans le cas de la Capitelle du Broum, d'un atelier métallurgique de taille incomparablement plus vaste.

À la Capitelle du Broum, il est plus difficile qu'à RoqueFenestre d'identifier avec certitude les galets plats à une cupule des galets-enclumes, et même des galets cassés à une cupule assimilables à des pics ou des enclumes. De toute façon, les diagrammes montrent que l'énorme domination des galets plats à double cupule est propre à RoqueFenestre, sans que l'on puisse privilégier une hypothèse chronologique plutôt que technologique.

Tous ces sites chalcolithiques, dont les plus importants sont tournés au moins pro parte vers des activités métallurgiques, confirment l'utilisation de ces outils à cupules dans la chaîne opératoire de transformation du minerai de cuivre en métal. Nous y reviendrons in fine.

En outre, leur absence dans les secteurs proprement miniers du district de Cabrières-Péret renforce cette idée. 

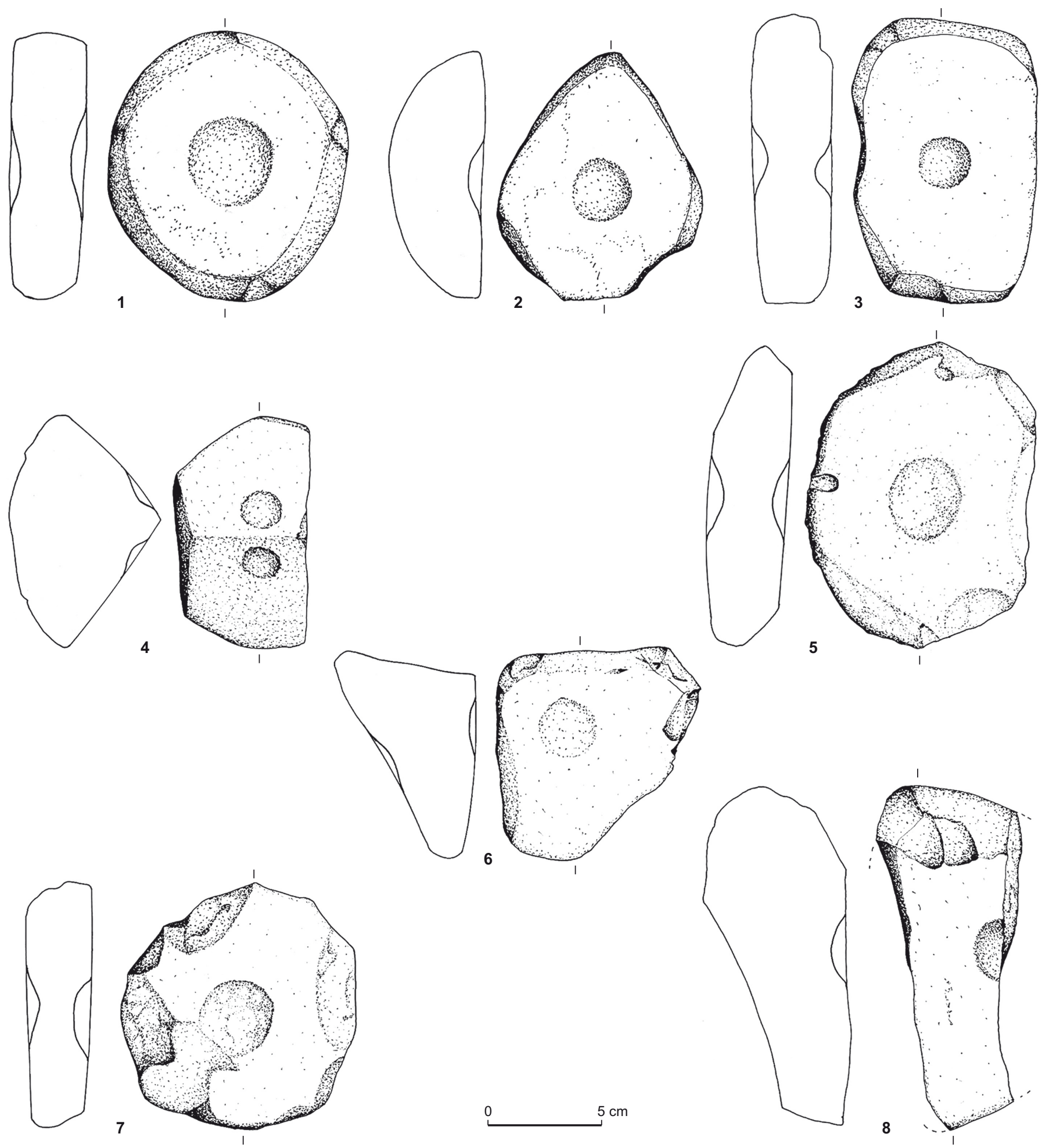

Fig. 2 - Sélection d'outils à cupules de Roque-Fenestre (Cabrières): 1, 3, 5, 7, outils plats à double cupule de type 1a (dont 5 et 7 sans martelage sur leurs tranches) ; 2, outil épais à une seule cupule et pointe percutante de type 2; 4 et 6, outils dièdres à double cupule de type 4; 8, "outil» enclume à une seule cupule de type 3; (1 à 3, 5 et 7, basalte; 4, 6 et 8, quartzite) (d'après J-L. Espérou, 1993). 

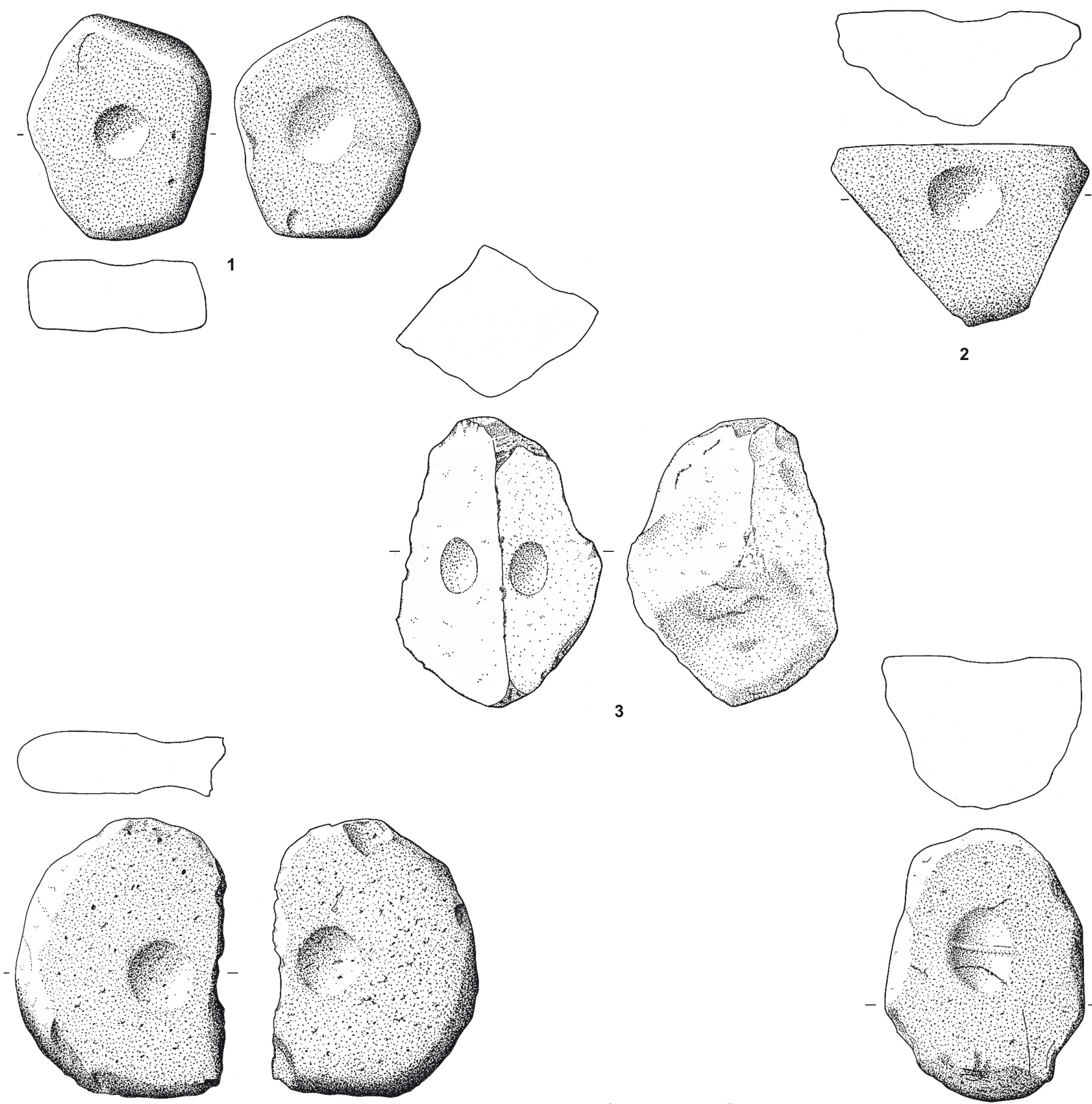

4
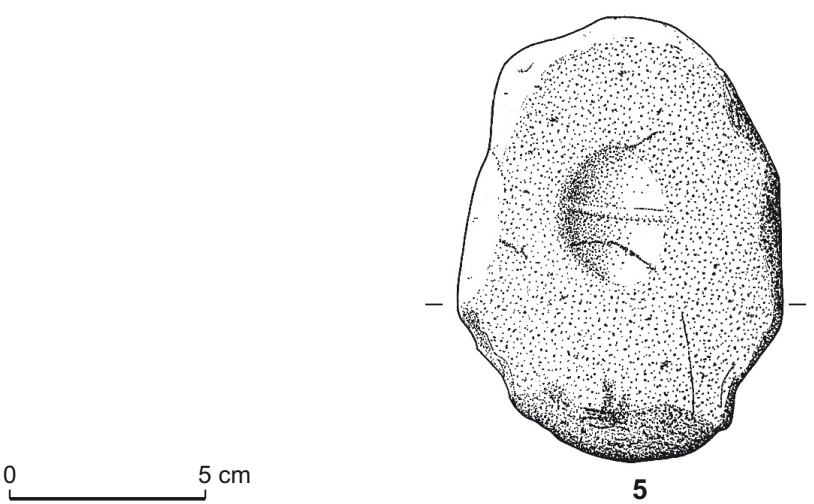

Fig. 3 - Sélection d'outils à cupule (s) de la Capitelle du Broum (Péret, Hérault): 1, outil plat à double cupule de type 1a; 2 et 5, outils épais de type enclume de type 3 (5, à bords martelés); 3, outil dièdre à double cupule de type 4; 4, outil plat à double cupule de type 1a; 1, grès, 2 et 3 quartzite, 4, basalte, 5, quartz (Dessins: J. Coularou). 
Tabl. I - Répartition des types d'outils à cupules dans les sites $d u$ district minier de Cabrières-Péret.

\begin{tabular}{|l|r|r|r|r|r|r|r|r|}
\hline \multicolumn{1}{|c|}{ Morphotype } & $\mathbf{1 a}$ & $\mathbf{1 b}$ & $\mathbf{2}$ & $\mathbf{3}$ & $\mathbf{4}$ & $\mathbf{5}$ & Indéterminé & Total \\
\hline La Capitelle du Broum & 13 & 16 & 3 & 5 & 3 & 4 & & $\mathbf{4 4}$ \\
\hline Roque-Fenestre & 7 & 5 & 1 & 1 & 3 & & 11 & $\mathbf{2 8}$ \\
\hline Valat Grand & 6 & 23 & & 1 & & & & $\mathbf{3 0}$ \\
\hline Le Cadenas & 1 & & & & & & & $\mathbf{1}$ \\
\hline Pioch-Farrus 438 & 1 & & & 1 & & & & $\mathbf{2}$ \\
\hline Pioch-Farrus 448 & 1 & 1 & & & & & & $\mathbf{2}$ \\
\hline Pitrous & & & & 1 & & & & $\mathbf{1}$ \\
\hline Roussignol & 1 & 1 & 1 & 1 & & & & $\mathbf{4}$ \\
\hline Indéterminés Total & & 3 & & & & & 1 & $\mathbf{4}$ \\
\hline \multicolumn{2}{|c}{} & $\mathbf{4 9}$ & $\mathbf{5}$ & $\mathbf{1 0}$ & $\mathbf{6}$ & $\mathbf{4}$ & $\mathbf{1 2}$ & $\mathbf{1 1 6}$ \\
\hline
\end{tabular}

Il est à ce titre significatif que Vasseur $(1911)^{2}$ ait pu ramasser 323 maillets de mineurs sur le plateau de Bellarade autour des mines préhistoriques des Neuf-Bouches sans rencontrer un seul de ces galets à cupules, et ce d'autant plus que les travaux menés postérieurement sur ce plateau (NeufBouches et le Petit Bois) ont confirmé ses résultats (Espérou et al., 1992; Ambert, 1995; Bouquet et al., 2006; Guendon et al., 2008). Le secteur minier de la Roussignole 12 est le seul site périphérique à l'exploitation minière à avoir fourni 4 outils à cupules associés à une centaine de maillets typiques de l'exploitation minière. La présence de ces galets à cupules en contexte minier permet de supposer soit l'existence d'activités métallurgiques sur le carreau de la mine, soit une utilisation de ces outils pour le concassage du minerai sur place avant déplacement sur le lieu de sa transformation.

\section{PROBLÈMES DE TERMINOLOGIE: DES GALETS À CUPULES AUX OUTILS À CUPULES}

À l'origine de la découverte de ces objets, nous avons utilisé le terme, en toute rigueur discutable, de galets à cupules. Peu d'entre eux ont à l'évidence pour supports de véritables galets qui indiqueraient un approvisionnement soit dans les terrasses d'une grande rivière comme l'Hérault, qui coule $5 \mathrm{~km}$ à l'est du district, soit dans une formation géologique d'origine alluviale, comme celle gréso-conglomératique du Trias qui affleure notamment à proximité de Péret. Ils forment même l'exception. Ils sont, pour la plupart, constitués de roches du socle des monts de

2. La sagacité de ce chercheur, professeur de Géologie à l'université de Marseille, ne peut être mise en cause, sa compétence doublée de son intérêt pour l'archéologie préhistorique ne faisant aucun doute.
Cabrières, dont la rivière principale, la Boyne, est largement intermittente et ne propose qu'exceptionnellement des alluvions bien roulées. C'est le cas d'un outil de la Capitelle du Broum, en roche locale, dont le fort émoussé peut avoir été façonné dans une «marmite de géant» du ruisseau du Broum.

Néanmoins, en l'absence de basalte sur le site, la très forte proportion d'objets de cette roche à Roque-Fenestre suggère que leur collecte s'effectuait dans les alluvions de la Boyne située immédiatement en contrebas. Elles contiennent en effet de nombreux éléments en roches volcaniques issus du bassin versant amont. Ces basaltes, ramassés en bord de rivière, sont mal façonnés par un transport relativement court; ce ne sont pourtant pas des galets puisqu'ils présentent deux faces planes héritées des fractures naturelles de la roche Il en est de même dans les sites du Valat Grand, nouvellement découverts en amont de Roque-Fenestre, sur la rive gauche de la Boyne.

En revanche, les outils à cupules de la Capitelle du Broum, à la pétrographie beaucoup plus variée que celle des autres sites, ont été dans leur majorité directement empruntés à des roches des affleurements avoisinants et à des blocs de basalte issus des alluvions du ruisseau du Broum. Ils ne prennent qu'exceptionnellement pour support des galets bien roulés par de puissantes rivières ou provenant de formations gréso-conglomératiques triasiques voisines (y compris originaires de la vallée de l'Hérault). C'est le cas de 10 pièces sur les 126 et, parmi elles, une grande majorité (6 exemplaires) est associée aux roches les plus siliceuses. À côté de ces dernières, il convient de noter 3 outils sur galets en grès gris du Viséen et 1 en basalte. Ils proviennent, eux aussi, du site de la Capitelle du Broum et ont pu être façonnés par les eaux du torrent local.

Aussi, nous proposons de remplacer le terme de galets à cupules, par celui d'outils à cupules, lequel renforce leur caractère fonctionnel et rend mieux compte de la diversité de leur condition de collecte.

\section{ÉTUDE PÉTROGRAPHIQUE DES OUTILS À CUPULES}

\section{LES DIFFÉRENTS TYPES PÉTROGRAPHIQUES SUR L'ENSEMBLE DES SITES}

L'analyse pétrographique des outils à cupules du district de Cabrières-Péret a porté sur un échantillon de 126 outils. On distingue différents types de roches: du basalte, des grès et des quartzites, ainsi que des roches calcaréo- 
dolomitiques. La plupart ont pu être rattachés à des formations géologiques régionales. Quelques outils, sortis de la collection pour d'autres études, n'ont pas pu être déterminés avec précision lors de notre analyse.

Le basalte est de loin la roche la plus fréquemment rencontrée avec 79 pièces, soit $63 \%$ de la collection. Ce basalte est issu des coulées volcaniques quaternaires abondantes autour de Cabrières. La plupart d'entre elles se situent à plusieurs kilomètres de nos sites de référence: vers le sud autour de Fontès, à l'ouest dans la commune de Montesquieu et au nord-ouest au dessus de Valmascle. Vers l'est, il existe d'autres manifestations volcaniques plus proches, entre Lieuran-Cabrières et Péret. Les matériaux de cet important affleurement, très près du site de la Capitelle du Broum, à peine plus de $500 \mathrm{~m}$, se retrouvent en outre largement remaniés dans les alluvions du ruisseau du Broum qui passe juste en contrebas de ce site. Cependant, nous verrons plus loin que cette forte représentation pétrographique est valable pour les outils à cupules provenant de tous les sites étudiés. Il y aurait donc bien là un choix préférentiel de cette roche pour ces outils spécifiques à l'activité métallurgique.

Parmi les roches gréseuses (22 objets, soit $18 \%$ de la collection), on distingue deux types d'origine locale.

- Avec 16 pièces, les grès fins, de couleur gris foncé, sont les plus abondants. C'est une roche dure, constituée de petits grains de quartz, mais dont le ciment est calcaire. L'origine est à rechercher dans la série des flyschs gréseux du Carbonifère local (Viséen terminal - h2b des cartes géologiques) largement affleurants dans tout ce secteur.

- Cette origine est également valable pour 4 outils en grès fin jaunâtre, riche en petits micas blanc, provenant de la Capitelle du Broum.

Les roches strictement siliceuses regroupent différents types: des grès quartzites, des grès schisteux, des quartzites et des quartz. Ces roches diverses, mais quasi exclusivement siliceuses, sont représentées par 13 pièces, soit $10 \%$ de l'ensemble.

- On note 4 pièces en différents grès quartzites. C'est une roche très dure, d'origine sédimentaire, plus ou moins métamorphisée, à ciment siliceux, dont la provenance est indéterminée, mais qui pourrait être relativement allochtone (2 étaient initialement de vrais galets alluviaux).

- 2 autres, sans doute également allochtones (toutes les deux façonnées sur des galets alluviaux), sont constituées par un grès schisteux et un grès siliceux lité (lits de micas noirs), provenant probablement tous les deux de la série infracambrienne épimétamorphisée du Lodévois.
- 5 outils sont en quartzite, de métamorphisme ou filonien, dont 1 sur galet.

- 2 sont en quartz filonien, dont 1 sur galet.

La forte proportion de galets parmi ces outils en roches siliceuses variées pourrait indiquer une provenance depuis les terrasses alluviales pliocènes ou quaternaires de l'Hérault; mais certains galets, de quartz notamment, peuvent avoir une origine plus proche et provenir de la série triasique qui renferme à sa base un conglomérat à éléments de quartz et de roches du Paléozoïque. Trois points sont à retenir en faveur de cette origine. Ce conglomérat fut utilisé pour la fabrication des nombreuses meules et molettes trouvées sur le site de la Capitelle du Broum. Ses affleurements les plus proches se situent autour de LieuranCabrières, à moins de $2 \mathrm{~km}$ de ce site préhistorique. C'est d'ailleurs le seul de tous les sites à avoir fourni des outils à cupules sur galets siliceux, mais aussi le plus proche des affleurements triasiques.

On observe également quelques objets en roches calcaréo-dolomitiques. Ils ne sont représentés que par 9 pièces, soit $7 \%$ de la collection. Cette faible représentation, pour des roches pourtant abondantes dans l'environnement local, renforce la notion de choix préférentiel notamment pour le basalte. Cela semble en effet logique au regard des caractéristiques mécaniques des calcaires et dolomies apparemment peu adaptées pour concasser et broyer des roches souvent plus dures. Il semble même curieux d'utiliser ces roches tendres pour ce type d'outils. Pourtant, leur morphologie, en tout point semblable aux autres outils à cupules, ne laisse planer aucun doute sur leur attribution. Il est vrai que certains grès, notamment les grès fins, jaunâtres et micacés du Viséen, ne semblent guère plus durs. Outre les raisons mécaniques que l'on vient d'évoquer, notre étonnement devant ces objets relève aussi du fait que ces roches s'altèrent et se corrodent facilement et qu'après 5000 ans passés dans le sol, les cupules de ces outils sont indiscutables et restent très bien marquées malgré une légère dissolution de surface. Il est dommage que cette altération superficielle handicape fortement l'étude tracéologique. Elle aurait pu nous renseigner sur les raisons de l'usage de cette roche relativement tendre. Quoi qu'il en soit, on dénombre 6 pièces en dolomie, 1 en calcaire fossilifère (sans doute un calcaire à encrines ou encrinite du Dévonien local -d3-4), 1 en calcaire bréchique (sans doute un calcaire dévonien local) et 1 en calcaire indéterminé.

Le choix du basalte semble donc prépondérant, tout comme l'utilisation de roches strictement locales, du moins 
Tabl. II - Les outils à cupule(s) du district de Cabrières-Péret. Répartition par site et d'après la pétrographie. Les pourcentages des différentes roches par sites sont exprimés en valeur relative.

\begin{tabular}{|c|c|c|c|c|c|c|c|c|c|c|c|c|}
\hline \multirow[t]{2}{*}{ Site } & \multicolumn{2}{|c|}{ Outils } & \multicolumn{2}{|c|}{ Basalte } & \multicolumn{2}{|c|}{ Grès } & \multicolumn{2}{|c|}{$\begin{array}{c}\text { Roche } \\
\text { siliceuse }\end{array}$} & \multicolumn{2}{|c|}{$\begin{array}{c}\text { Roche } \\
\text { carbonatée }\end{array}$} & \multicolumn{2}{|c|}{ Indét. } \\
\hline & $\%$ & $\mathrm{Nb}$ & $\%$ & $\mathrm{Nb}$ & $\%$ & $\mathrm{Nb}$ & $\%$ & $\mathrm{Nb}$ & $\%$ & $\mathrm{Nb}$ & $\%$ & $\mathrm{Nb}$ \\
\hline La Capitelle du Broum & 43 & 54 & 46 & 25 & 28 & 15 & 13 & 7 & 13 & 7 & c & 0 \\
\hline Roque-Fenestre & 21 & 27 & 74 & 20 & \multicolumn{2}{|c|}{0} & 15 & 4 & \multicolumn{2}{|c|}{0} & 11 & 3 \\
\hline Valat Grand & 24 & 30 & 83 & 25 & 10 & 3 & 3 & 1 & 3 & 1 & \multicolumn{2}{|c|}{0} \\
\hline Autres & 12 & 15 & \multicolumn{2}{|c|}{9 pièces } & \multicolumn{2}{|c|}{4 pièces } & \multicolumn{2}{|c|}{1 pièce } & \multicolumn{2}{|c|}{1 pièce } & \multicolumn{2}{|c|}{0} \\
\hline Total & 100 & 126 & 63 & 79 & 18 & 22 & 10 & 13 & 7 & 9 & 2 & 3 \\
\hline
\end{tabular}

proches, qui offrent il est vrai une assez large palette depuis des matériaux durs et abrasifs jusqu'à des roches plus tendres. Ainsi, 110 pièces sont en roches nettement autochtones, ce qui représente $87 \%$ de la collection, ainsi que certains galets de quartz et roches siliceuses qui pourraient provenir des conglomérats triasiques voisins. Les roches très proches, situées à moins de $2 \mathrm{~km}$ des sites, constitueraient donc plus de $90 \%$ des sources d'approvisionnement.

\section{RÉPARTITION PÉTROGRAPHIQUE PAR SITES}

Parmi les 126 outils que nous avons étudiés, 111 proviennent de seulement trois sites: 54 (43\%) de la Capitelle du Broum, 30 (24\%) de Valat Grand et 27 (21\%) de Roque-Fenestre. Il faut cependant noter que, si le site de la Capitelle du Broum est numériquement le plus riche, c'est aussi celui qui a connu la fouille la plus extensive, et que celui de Valat Grand, qui arrive néanmoins en seconde position par le nombre de galets à cupules, est très érodé et n'a quasiment pas été fouillé. Ces éléments sont à retenir dans l'analyse qui va suivre (tabl. II).

À la Capitelle du Broum, la proportion de basaltes (25 pièces soit $46 \%$ ) reste importante, mais semble inférieure par rapport à celle des autres sites. Pourtant, parmi les trois sites principaux, c'est celui qui est le plus proche d'un affleurement volcanique. Corrélativement, le pourcentage des grès viséens est important avec 15 pièces sur les 22 façonnées dans cette roche. Il est vrai que cette roche affleure largement juste en contrebas du site. Mais, faut-il seulement retenir un opportunisme de prélèvement lié à la proximité des matériaux, alors que dans les deux autres sites la faible utilisation, voire l'absence de cette roche dans les outils ne semble pas liée à un éloignement notable des affleurements naturels?
En effet, bien que le Viséen se développe largement juste en contrebas du site de Roque-Fenestre, les roches de cette formation ne semblent pas y avoir été utilisées. La présence de basalte aurait pu indiquer une récolte strictement opportuniste si leur proportion n'était pas aussi importante dans l'assemblage (74\%, soit 20 pièces sur les 27 de ce gisement). Elle indique ainsi plutôt une sélection préférentielle de blocs de basalte provenant des alluvions des deux ruisseaux en contrebas du site, le Broum et la Boyne, arrachés aux affleurements situés en amont des bassins versants. Par ailleurs, l'utilisation de roches siliceuses de type quartzite pourrait être en relation avec la proximité du filon siliceux qui domine le site et qui est à l'origine de l'appellation du lieu-dit, d'autant qu'ici les objets en roches siliceuses n'ont pas été façonnés à partir de galets.

Le site de Valat Grand serait celui qui, dans l'état actuel des recherches, fournirait la plus grande proportion relative d'objets en basalte. Là aussi, les affleurements primaires de cette roche sont assez éloignés (coulées au-dessus de Valmascle) mais, encore une fois, la Boyne, ruisseau pourvoyeur en matériaux remaniés, coule à proximité du site. Dans les autres sites (Pioch-Farrus 448, la Roussignole, le Cadenas et Pitrous), qui regroupent 10 des outils classés «autres» dans le tableau I, les basaltes constituent la moitié des objets. Le reste associe les autres roches classiques du corpus des galets à cupules: 3 en grès, 1 en quartz et 1 en calcaire.

Malgré un nombre d'outils parfois faible, cette analyse laisse quand même transparaître un ou deux faits évidents et suggère quelques hypothèses. Tout d'abord, les trois gisements principaux montrent une parenté évidente: les corpus pétrographiques y sont relativement similaires. L'utilisation du basalte est partout prépondérante. Cette roche était sans doute la mieux adaptée (par sa dureté, sa morphologie ou son grain) aux fonctions des outils à cupules. Elle est également partout présente dans l'environnement proche des sites considérés. Mais, pour le basalte, comme pour la majorité des autres matériaux utilisés, l'idée d'un prélèvement opportuniste n'apparaît pas strictement évidente. Feraient exception quelques cas particuliers évoqués plus haut, portant sur un petit nombre d'objets et uniquement sur une variété au sein d'un même groupe pétrographique: galets de quartz triasiques de la Capitelle du Broum et blocs de quartzite du filon de Roque-Fenestre. La sélection taphonomique liée à l'altérabilité différentielle des roches ne semble pas également avoir eu un rôle quelconque. La présence d'outils à cupules calcaréo-dolomitiques relativement bien conservés en témoigne. 
Bien qu'en proportions plus faibles, d'autres roches plus tendres (grès viséens, calcaires et dolomies) ou, au contraire, plus dures (quartz, quartzites) apparaissent systématiquement à côté des basaltes. Si l'on admet l'idée d'un prélèvement non-aléatoire des matériaux, les différentes roches constituant les outils à cupules pourraient correspondre à des choix pétrographiques. Ils seraient liés à des caractères mécaniques et/ou morphologiques peut-être en relation avec des fonctions différentes.

\section{CLASSIFICATION ET CARACTÉRISTIQUES TECHNOTYPOLOGIQUES DES OUTILS À CUPULES}

L'étude typologique et fonctionnelle des outils à cupules repose sur un échantillon représentatif de 116 outils, soit 10 de moins que pour l'étude pétrographique des pièces. Cela s'explique par la présence d'outils dont la matière première était à ce point altérée que les surfaces de travail n'étaient plus identifiables en tant que telles. Ces outils proviennent des différents sites liés à l'extraction et à la métallurgie du cuivre dans le district de Cabrières-Péret: la Capitelle du Broum (44 ex.), Roque-Fenestre (28 ex.), Valat Grand (30 ex.) ou encore Pioch-Farrus 338 et 348, la Roussignole et Pitrous ( $c f$. annexe 1$)$.

\section{PRINGIPALES GARACTÉRISTIQUES DES OUTILS À CUPULES ET RAPPEL DES TRAVAUX PRÉCÉDENTS}

Plusieurs outils à cupules de la Capitelle du Broum ont été précédemment décrits par C. Cert qui leur reconnaît un certain nombre de caractères constants, en sus de la/les cupules qui permet de les identifier (Cert, 2003 et 2005). L'auteur différencie des galets plats, peu épais $(3 \mathrm{~cm})$ aux faces subparallèles, de formes plus épaisses, dont certaines, qui possèdent une arête formant un dièdre entre les faces portant cupules, restent quelque peu énigmatiques (Cert, 2005).

Un certain nombre d'outils à cupules montre des faces planes qui témoignent d'actions d'abrasion sinon de broyage. D'autres peuvent avoir joué le rôle d'enclume. Les extrémités, une ou plusieurs plages sur les faces de ces pièces et parfois leur pourtour, ont été utilisés pour la percussion. Les cupules disposées au centre des faces planes ont été attribuées dès l'origine à une activité métallurgique, sans que leur fonction ait pu être précisément déterminée (Espérou, 1988). La majorité des pièces planes à large surface de travail privilégie le basalte, plus fragile au choc, mais qui possède une meilleure acceptation thermique s'accordant avec la chauffe qu'ont subie plusieurs de ces outils.

Enfin, il convient de souligner plusieurs caractéristiques essentielles qui différencient les outils à cupules des maillets de mineur. Ces derniers, hormis quelques rares utilisations du basalte, sont façonnés dans les roches les plus dures du district minier: quartzite et quartz filoniens locaux. Les roches purement siliceuses sont au contraire rarement utilisées pour les outils à cupules et, quand c'est le cas, les matériaux ont généralement une origine différente. En effet, dans la série des outils à cupules examinée, quelques unités seulement pourraient provenir des formations filoniennes siliceuses locales. Dans leur très forte majorité (tabl. II), les outils à cupules utilisent le basalte, voire les grès, qui sont des roches relativement plus tendres. C'est un point commun avec les pierres à cupules de Saint-Véran dans les Hautes-Alpes (Barge et al., 1998a).

Quel que soit le type auquel les outils à cupules se rapportent, leur forme est la plupart du temps directement héritée des diaclases des roches auxquelles ils ont été empruntés: préférentiellement grès et basalte. Parfois, des fragments de roche de plus grand volume sont utilisés. Ils subissent alors un débitage de tout ou partie de leurs pourtours. Ces outils sont donc façonnés dans des matériaux locaux. Néanmoins, les pièces dièdres à double cupule ( $c f$. infra, fig. 4-4) forment une exception notable, puisqu'elles sont toutes en quartzite; les pièces épaisses de tous les types définis infra utilisent aussi cette roche ou le quartz, qui semble souvent d'origine plus allochtone. Il faut croire qu'elles devaient avoir une utilisation spécifique et servir là où les autres types d'outils à cupules devaient s'avérer inopérants.

\section{CLASSIFICATION TECHNOMORPHOLOGIQUE DES OUTILS À CUPULES}

Dès l'origine de la découverte des outils à cupules (Ambert et al., 1984; fig. 4), la diversité de leur forme, évidente, s'est imposée à nous. Elle a permis de différencier plusieurs types, lesquels, en l'absence jusqu'ici d'études tracéologiques, ont servi de base de classification à tous les travaux qui leur ont été consacrés (Espérou, 1988 et 1993; Espérou et al., 1994; Cert, 2003 et 2005). Une révision de cette classification initiale des outils à cupules peut désormais être proposée sur la base des critères de matière première, de morphologie et de localisation des traces de fabrication et d'utilisation ( $c f$. infra, p. 193). Cette classification ne repose pas sur une distinction percutant/ 


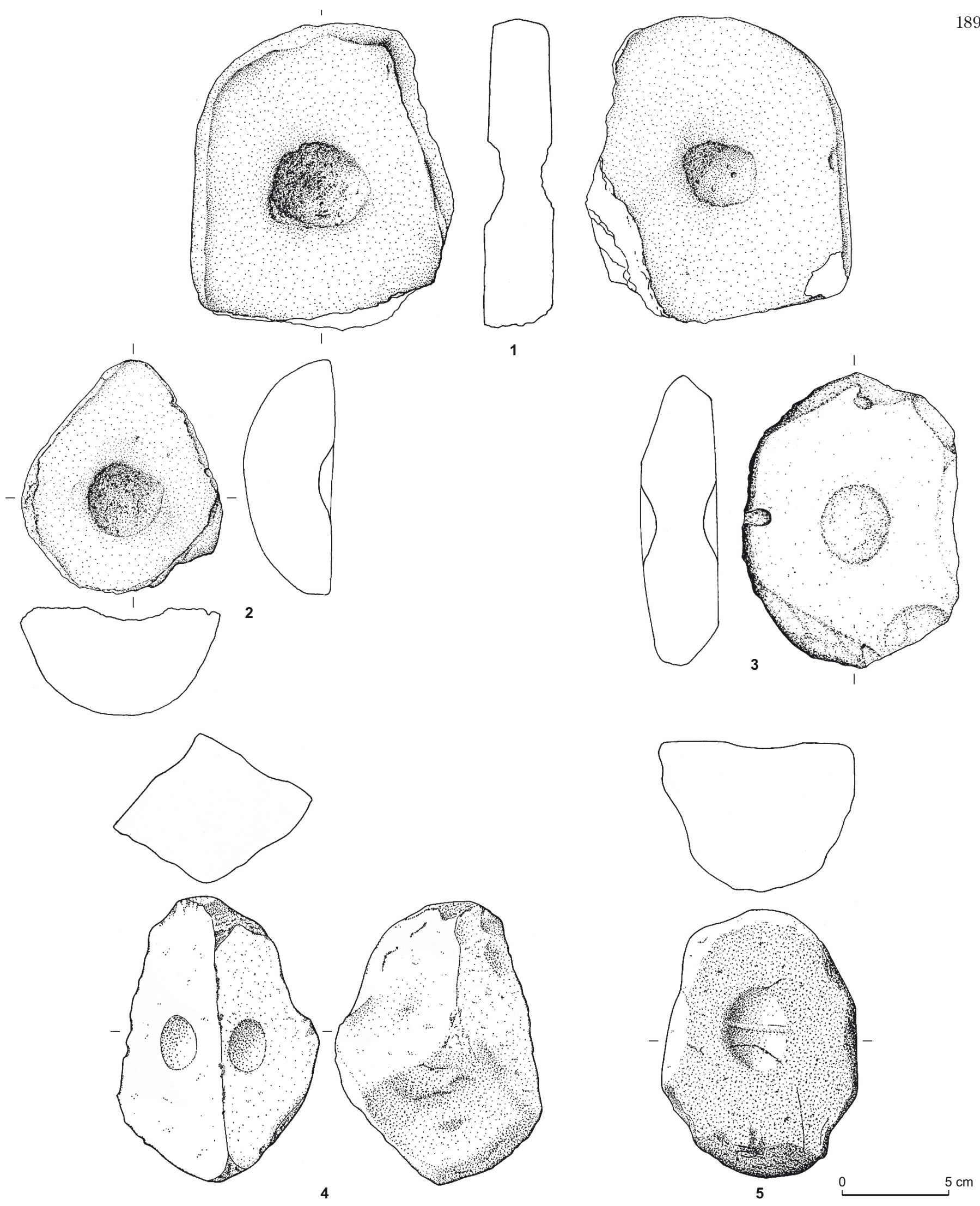

Fig. 4 - Principaux types d'outils à cupule(s) du district minier-métallurgique de Cabrières-Péret (Hérault): 1, outil plat à double cupule de type 1a (basalte); 2, outil épais à une seule cupule et pointe percutante de type 2 (basalte); 3, outil plat à double cupule, sans martelage périphérique de type 1a (basalte); 4, outil dièdre à double cupule de type 4 (quartzite); 5. outil épais de type enclume de type 3 (quartz). Les $n^{\text {os }} 1$ et 2 portent des mouchetures d'oxydes de cuivre de couleur verte liée à leur utilisation (Dessins: J. Coularou). 
répercutant, car l'attribution des outils à cupules à l'un ou l'autre de ces types apparaît problématique à de nombreux égards ( $c$. infra, p. 199). De même, le nombre de cupules ne nous est pas apparu un critère fondamental de distinction entre chacun des types d'outils, puisqu'il ne modifie en rien l'utilisation de l'objet.

Sur ces bases, cinq grands types technotypologiques ont pu être définis.

\section{TYPE 1}

Outils ovoïdes à section rectangulaire peu épais, dont les faces présentent une ou deux cupules et la tranche porte des impacts de percussion:

a) outils à double cupule majoritairement en basalte. Les faces actives présentent des traces couvrantes de broyage et une tranche densément percutée;

b) outils à faces planes ou convexes dont les tranches peuvent présenter un piquetage épars en alternance avec des enlèvements périphériques. Ils présentent au moins une cupule de percussion.

Ce type regroupe $80 \%$ des pièces prises en compte dans cette étude. Il s'agit à l'évidence, comme le soulignera infra l'analyse technofonctionnelle, d'outils à fonctions multiples (broyage, abrasion, concassage), pouvant servir alternativement de façon passive ou lancée. Le caractère très élaboré de certains des exemplaires découverts à Roque-Fenestre (fig. 5 et 6), compte tenu du martelage intense qu'ont subi leurs périphéries proximale et distale, nous a fait privilégier l'hypothèse de percuteurs à cupules. Certains exemplaires du type $1 \mathrm{~b}$ sont quasiment circulaires puisqu'ils ont servi sur tout leur pourtour.

\section{TYPE 2}

Outils épais à section rectangulaire ou semi-circulaire et face plane, qui présentent une cupule centrée et une face avec un poli très développé. Une ou plusieurs de ses extrémités percutées présentent généralement des formes appointées adaptées à un geste soigné et précis. Ces outils se caractérisent par une certaine dissymétrie dans la localisation des plages d'utilisation.

Le type 2 est représenté par 7 outils: 1 exemplaire à Roque-Fenestre (fig. 7), 1 exemplaire près de la mine 12 de la Roussignole, 1 indéterminé et 4 à la Capitelle du Broum. Outre leur forme très caractéristique et leur taille relativement standard (fig. 7), les outils du type 2 présentent des traces cuivreuses à la périphérie de l'extrémité appointée qui

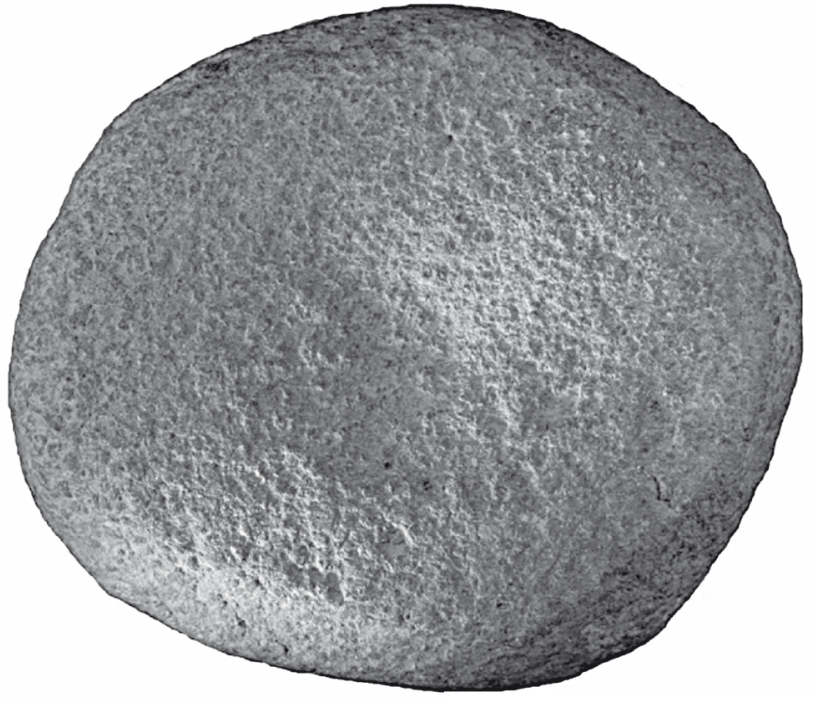

II

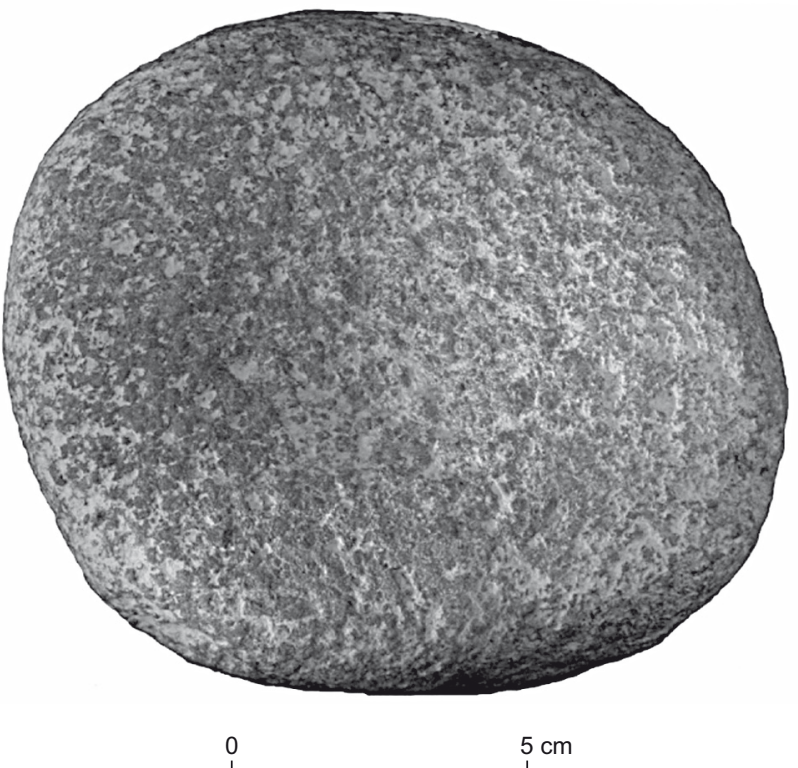

Fig. 5 - Galet à cupules (avers et revers) de type 1a, Roque-Fenestre, Cabrières (Cliché: C. Requirand 2007).

confirment leur utilisation comme percuteurs. Il convient d'attirer l'attention sur la similarité de forme et de taille de 3 pièces provenant de trois sites différents (Roque-Fenestre, la Roussignole 12, la Capitelle du Broum).

Leur pétrographie variée (basalte, grès, dolomie silicifiée) montre qu'ils n’ont généralement pas été sélectionnés dans les roches les plus dures de la palette locale. En effet, le très bel exemplaire, issu d'un galet de quartz, découvert à la Capitelle du Broum (Cert, 2005, fig. 1, n 4), fait pour le moment exception. 


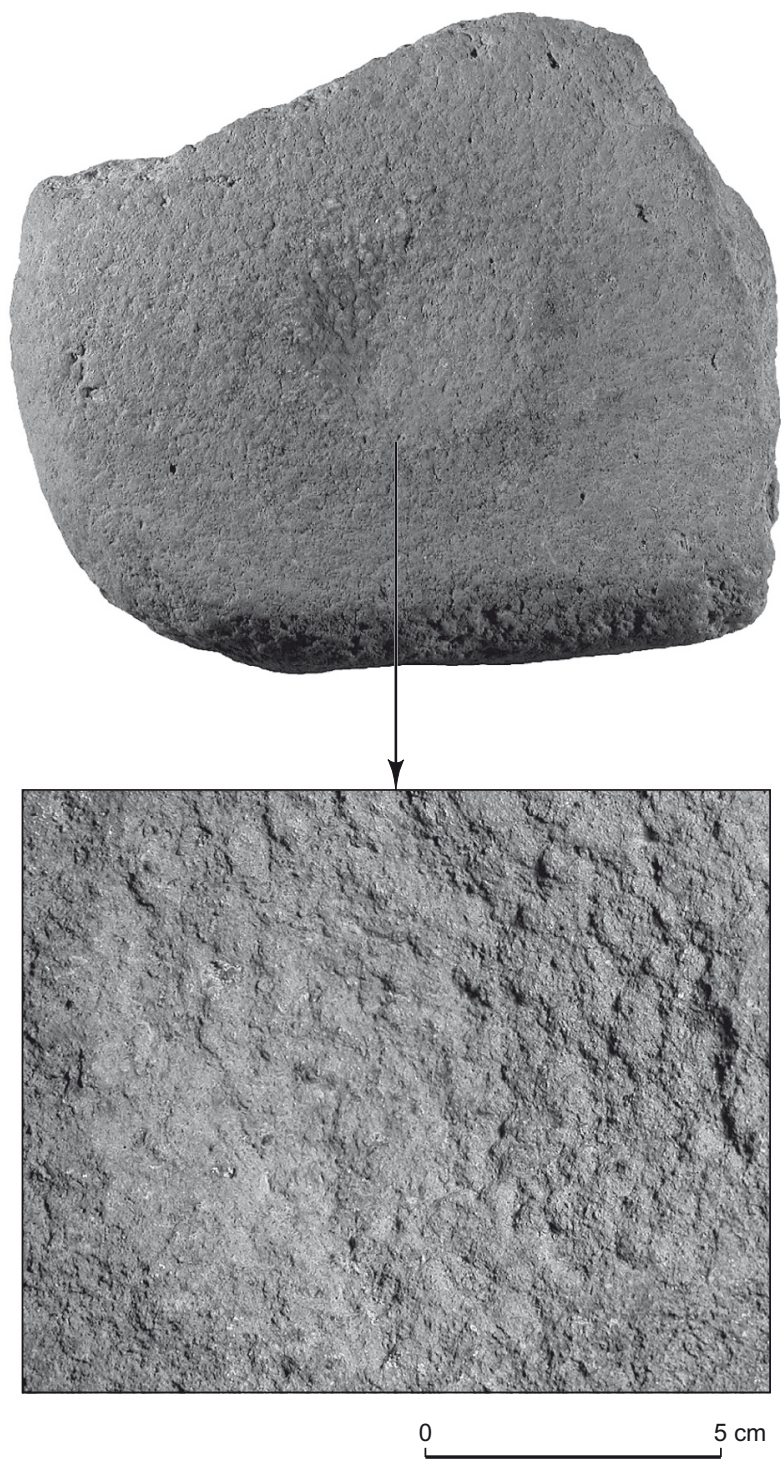

Fig. 6 - Galet à cupules de type la avec des traces punctiformes de cuivre dans la cupule. Roque-Fenestre, Cabrières (Cliché: C. Requirand 2007).

\section{TYPE 3}

Outils massifs sur plaque de grès, dont les faces, souvent polies, parfois piquetées, présentent de une à deux cupules. L'aspect massif de ces outils nous a longtemps conduits à les considérer comme des enclumes de petite taille.

a) outils sur plaques de grès de forme anguleuse aux tranches brutes;

b) outils trapézoïdaux dont les bords sont bruts ou façonnés et les arêtes probablement retouchées.

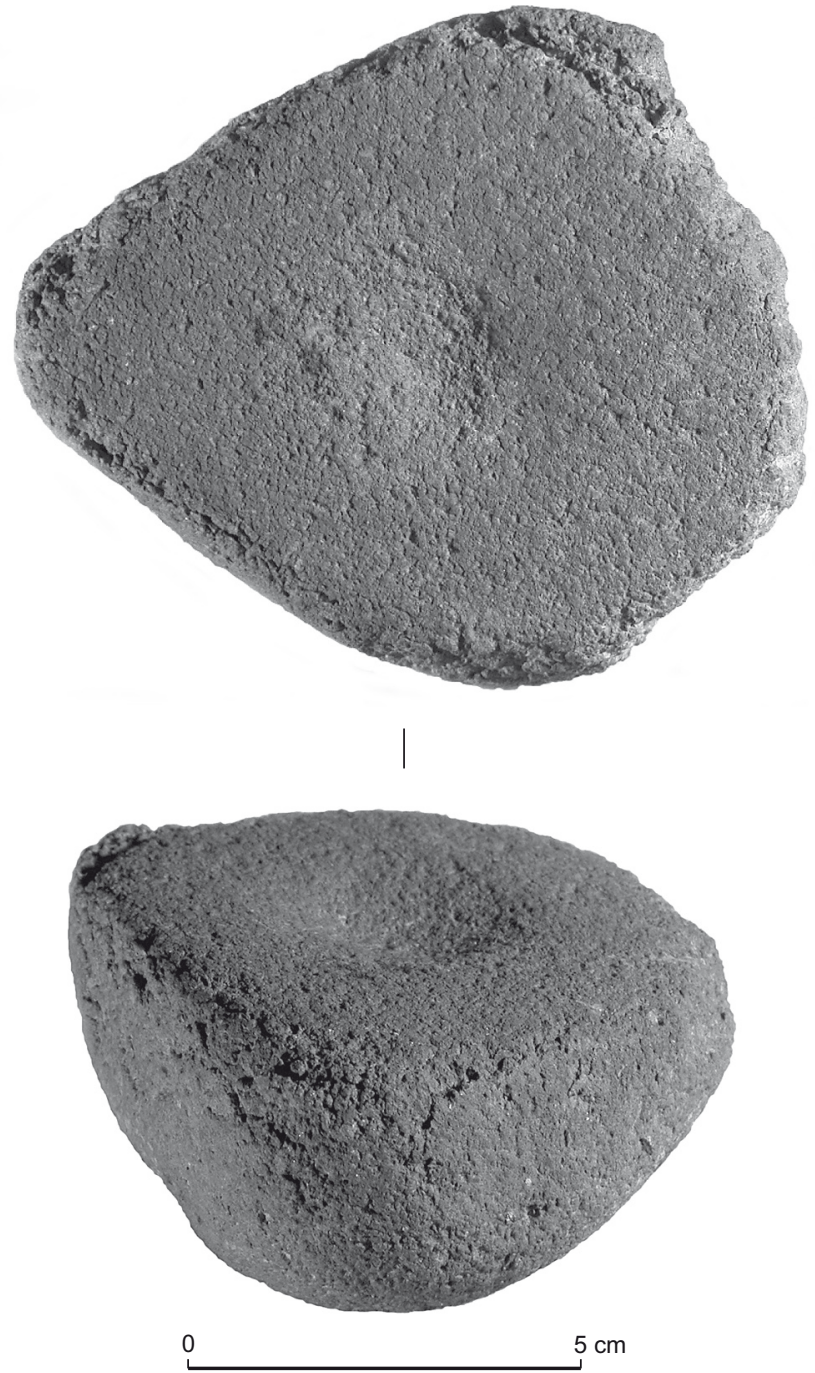

Fig. 7 - Galet à cupule de type 2 (face et profil), Roque-Fenestre, Cabrières (Cliché: C. Requirand 2007).

Le type 3 est, pour sa part, représenté par un seul exemplaire dans 5 sites différents (Valat Grand, Roque-Fenestre, Pitrous, Pioch-Farrus 438 et la Roussignole 12), les derniers outils provenant de la Capitelle du Broum. Le plus bel exemplaire, en quartz, provient de la Capitelle du Broum (Cert, 2003, fig. 2, $\mathrm{n}^{\circ} 1$ ). L'unique cupule, nette, bien que peu marquée du fait de la dureté de la roche, occupe sensiblement le centre de la face plane.

Toutes les pièces, plus épaisses et à faces moins régulières que les artéfacts du type 1 , ne portent qu'une seule 
cupule centrale sur leur face la plus aplanie. Dans ce type, il convient de citer:

- l'un des deux galets à cupules de Pioch-Farrus 448 (Espérou et al., 1994, fig. 4, $\mathrm{n}^{\circ} 1$ ), pièce «dont le revers est entièrement cassé », mais dont l'épaisseur et la forme générale le rapprochent de l'exemplaire type (Cert, 2003, fig. $\left.2, \mathrm{n}^{\circ} 2\right)$;

- les exemplaires, moins épais mais à une seule cupule, de Roque-Fenestre (Espérou, 1993, fig. 11, nº 8 et fig. 12, n 5), qui ne sont pas très éloignés d'un exemplaire de la Capitelle du Broum (Cert, 2003, fig. 3, n 5).

Ainsi, comme nous le supposions précédemment au sujet de l'exemplaire type de cette catégorie, ces objets pouvaient être calés ou posés au sol. Ils devaient alors avoir un rôle passif, peut-être associé au rôle actif, lancé, de percuteur des objets de type 1 . Vient à l'appui de cette remarque le fait que deux outils en quartz provenant, l'un de la Capitelle du Broum, l'autre de la Roussignole 12, ont éclaté axialement en deux au niveau de leur unique cupule.

\section{TYPE 4}

Outils dièdres de section semi-circulaire dont les cupules sont disposées sur chacune des faces planes majoritairement polies.

Ce type n'est représenté que par 6 exemplaires tout à fait surprenants. Il avait déjà été rencontré à Roque-Fenestre (Espérou, 1993, pl. II-4), dont les 3 exemplaires ont été précédemment décrits sous le nom de galets en forme de dièdre (Espérou, 1988), mais aussi de galets à crête (Cert, 2005). Deux autres proviennent de la Capitelle du Broum et un dernier est d'origine inconnue. Ces pièces présentent deux faces planes qui se rejoignent par un angle plus ou moins marqué ou au contraire ouvert. L'utilisation de l'outil modifiant peu la forme initiale du bloc, ce sont les diaclases originelles de la roche qui déterminent la forme et l'angulation du dièdre. Les deux faces les plus larges portent l'une et l'autre une cupule symétrique par rapport à l'arête dièdre. Aucun des 6 exemplaires entiers identifiés ne présente une morphologie identique, rendant encore plus délicate leur affectation à un type de travail précis. Parmi eux, 3 sont tirés de quartzite très durs, 2 autres sont en basalte, le dernier en grès. Seules les cupules permettent de les rattacher aux outils que nous étudions ici. La position des cupules par rapport aux faces du dièdre n'est pas constante. La plus spectaculaire, la plus souvent représentée, avec ces deux cupules qui jouxtent l'arête, est, de fait, l'outil le plus difficile à interpréter (fig. 8). Plusieurs

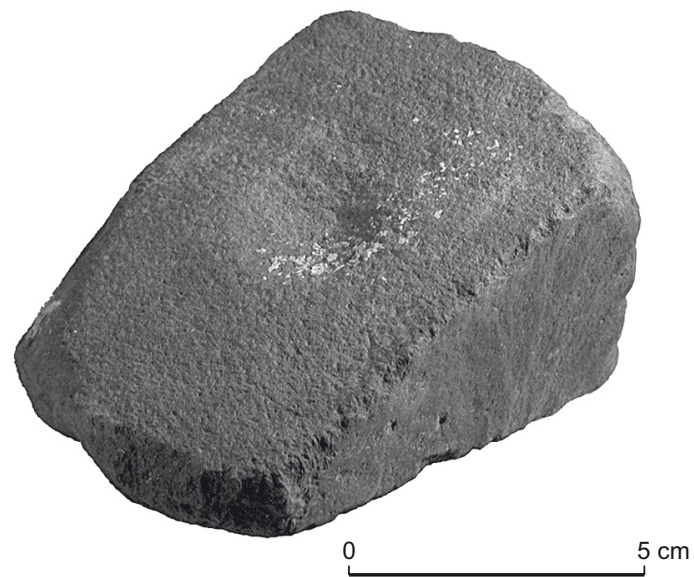

Fig. 8 - Galet à cupules dièdre de type 4 (Cliché: C. Requirand 2007).

d'entre eux portent de surcroît des marques de martelage sur les extrémités de l'arête médiane. C'est le cas de l'un des exemplaires de la Capitelle du Broum. Cela peut bien sûr relever d'une utilisation secondaire, opportuniste, de cet outil très dur. À Roque-Fenestre, deux autres outils présentent des cupules mieux centrées sur les deux faces du dièdre (fig. $4, n^{\circ} 4$ ). Comme le suppose C. Cert, ces outils peuvent avoir servi de microenclumes, comme certains des exemplaires de type 3 , mais cette hypothèse n'explique pas la recherche d'une symétrie des cupules par rapport à l'arête (Cert, 2005).

\section{TYPE 5}

Outils en dolomie à une ou deux cupules de percussion, de section quadrangulaire, dont les tranches façonnées présentent une percussion couvrante. Les surfaces sont globalement altérées. Ce type rassemble seulement 4 outils à cupules retrouvés à la Capitelle du Broum.

\section{CARAGTÉRISTIQUES PÉTROGRAPHIQUES PAR TYPES D'OUTILS À CUPULES}

Les basaltes sont nettement majoritaires dans le type 1, avec $86 \%$ des outils, tandis que les autres roches dominent dans les types 3 et 4 , avec notamment cinq pièces de grès et quartzites sur sept pour le type 3 et quatre pièces sur six pour le type 4. L'emploi des roches dures (quartzite, quartz, microgranite) est beaucoup plus exceptionnel. Ces proportions, peu représentatives en raison du faible effectif de certains types, montrent cependant une nette relation entre la pétrographie et la morphologie: les basaltes sont 
inféodés aux formes plates tandis que les grès et les quartzites le sont aux formes plus épaisses. Ce constat est particulièrement évident pour le type 1 qui regroupe 61 outils en basalte sur les 71 recensés dans les différents types. Cette relation tient évidemment à la morphologie naturelle des blocs de basalte, qui se présentent généralement sous forme de petites dalles. Néanmoins, cette forme naturelle peut avoir été un critère sélectif pour des raisons pratiques liées à la stabilité d'un objet plat et à l'utilisation évidente des surfaces planes lors des opérations de broyage par abrasion. Mais, là aussi, comme dans le choix de matériaux plus durs ou plus tendres, d'autres formes ont semble-il été recherchées. Ainsi, tout en étant globalement adaptées à l'environnement géologique proche, les différentes variétés pétromorphologiques utilisées pour la confection des outils à cupules ne semblent pas résulter de récoltes aléatoires, à l'exception de quelques cas particuliers, et cela quel que soit le site étudié. Cependant, il est difficile, en l'état actuel des travaux, de relier ces choix pétro-morphologiques à des fonctions particulières en relation avec les étapes d'une éventuelle chaîne opératoire.

\section{ANALYSE TECHNOFONCTIONNELLE DES OUTILS À CUPULES}

\section{FAÇONNAGE ET QUESTION DU PRÉFORMAGE DES CUPULES}

Les modes de façonnage et les traces de mise en forme sont partiellement dépendants des types de matières premières (basalte, grès, dolomie) et des supports (galets, plaquettes, fragments) sélectionnés pour la confection des outils à cupules. Il semble que la dureté des matériaux, somme toute assez variée, n'ait pas constitué un critère de choix exclusif au contraire de leur poids, de leur épaisseur et de leur morphologie. Ces trois paramètres semblent avoir joué un rôle bien plus important. Un schéma de mise en forme général peut ainsi être proposé. Il se réduit le plus souvent à un aménagement grossier par détachement d'éclats de la tranche des objets, parfois associé à une régularisation succincte par piquetage de la surface active. Sur certains objets, les impacts de percussion viennent directement entamer la surface naturelle. La forme parfaitement ovoïde de certains exemplaires d'outils à cupules (type 1) serait donc le fruit d'une utilisation prolongée en percussion lancée sur toute la tranche de l'objet (fig. 9). Contrairement à ce qui a pu être proposé précédemment (Cert, 2003), elle ne serait pas liée à un façonnage particulièrement poussé de ces objets. Seules les extrémités percutées de certains outils à cupules pourraient avoir fait l'objet d'un façonnage particulier par détachement d'éclats afin de créer un effet de dégagement, voire de pointe ( $c f$. type 2 ).

Les dimensions des cupules sont relativement régulières: leurs diamètres (compris entre $3 \mathrm{~cm}$ et $4 \mathrm{~cm}$ ) et leurs profondeurs (de $0,2 \mathrm{~cm}$ à $1 \mathrm{~cm}$ ) semblent en outre être proportionnels. Considérant qu'une surface plane piège plus difficilement la matière à concasser qu'une surface creuse, la question d'un éventuel préformage de la cupule s'est posée. Elle a été avancée pour les outils à cupules de Roque-Fenestre (Espérou, 1993, p. 45). D’un point de vue ethnographique, deux cas de figure sont documentés pour la formation des cupules: elle peut être préformée ou se creuser au cours de l'utilisation de l'objet (de Beaune, 2000).

Plusieurs arguments plaident néanmoins en faveur du creusement progressif de cette cupule au cours de l'utilisation des outils. Les cupules sont formées d'une juxtaposition d'impacts successifs, de formes et de dimensions souvent irrégulières (fig. 10). Elles ne sont pas systématiquement centrées sur l'objet, mais sont parfois décalées sur les faces des outils, ce qui contredit l'idée d'un préformage. La corrélation entre diamètre et profondeur des cupules suit tous les gradients de creusement: ceci signifie que l'utilisation ne déforme pas les cupules, mais entretient au contraire leur régularité. Enfin, les outils à faible durée d'utilisation (surfaces actives à peine arasées) présentent des cupules de moindres dimensions et inversement pour les outils à durée et intensité d'utilisation plus importantes. Il semble donc que les dimensions des cupules de percussion soient proportionnelles à la durée d'utilisation des outils, et que les cupules n'aient pas été préformées avant leur utilisation.

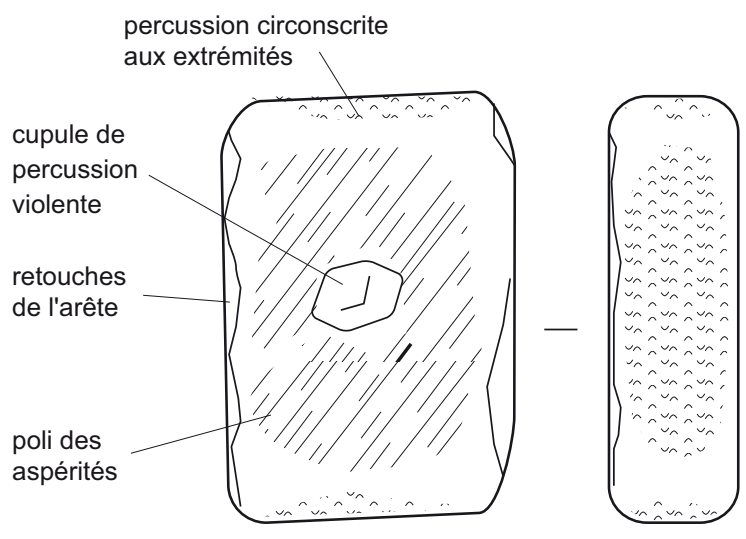

Fig. 9 - Localisation schématique des traces d'utilisation sur les outils à cupules du site de la Capitelle du Broum (Dessin: C. Hamon). 


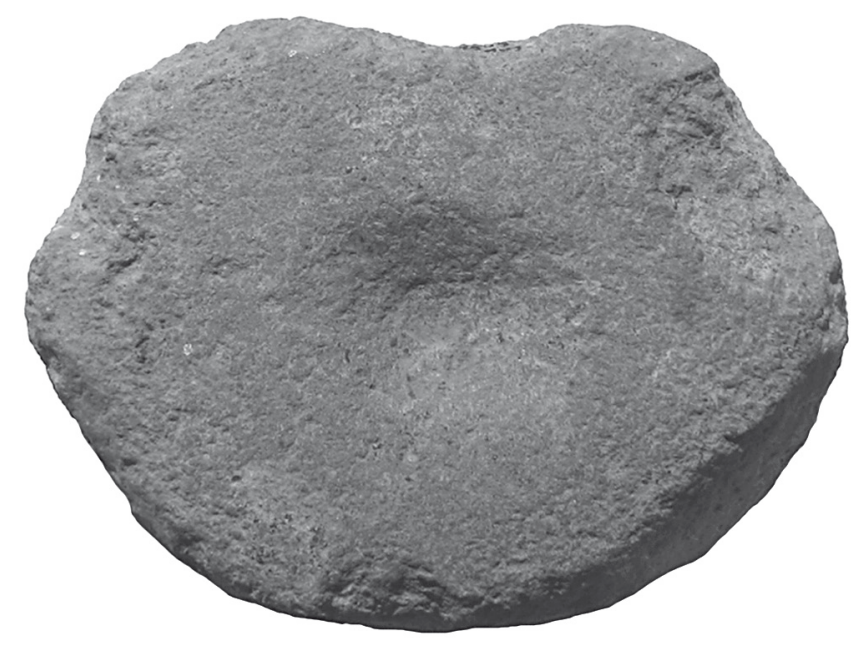

1

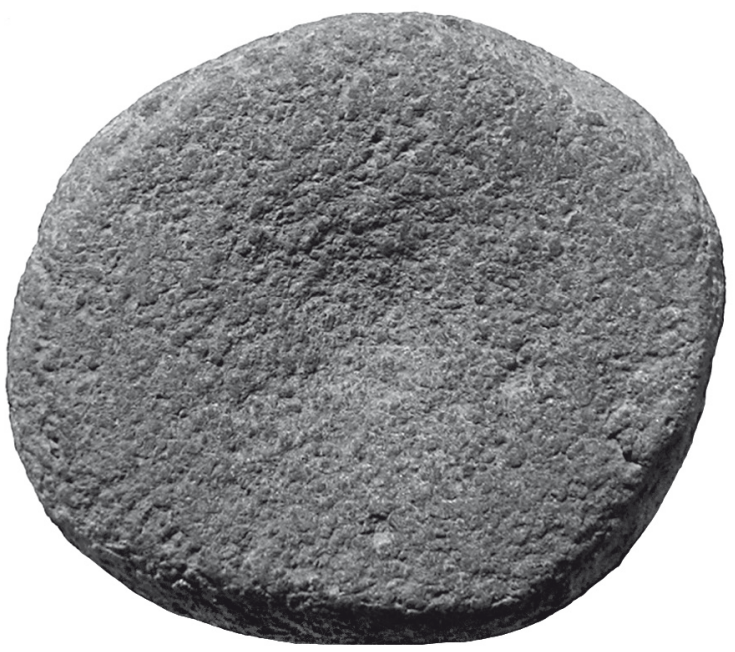

2

0 $5 \mathrm{~cm}$

Fig. 10 - Outils à cupule à longue durée d'utilisation: 1, la Capitelle du Broum, type 1b; 2, Roque-Fenestre type 1a. L'outil (2) est le stade d'utilisation ultime de l'outil (1). L'outil (1) présente encore des enlèvements de façonnage sur les bords, tandis que la tranche de l'outil (2) présente une fine percussion couvrante. La face de l'outil (2) est bien plus régularisée par l'usage et plus longuement utilisée que l'outil (1). La cupule de percussion de l'outil (1) présente encore des entailles de percussion initiale tandis que celle de l'outil (2) ne présente que de fins impacts de percussion (Clichés: C. Hamon).

Le façonnage, même succinct, des outils à cupules assure donc leur efficacité puisqu'il leur confère une morphologie adaptée, soit à leur calage, soit à leur prise en main. Il permet également de dégager les différentes plages d'utilisation, tranches et faces.

\section{LES DIFFÉRENTES TRACES OBSERVÉES}

\section{LES TRACES DE CHAUFFE}

Comme l'ont déjà souligné plusieurs auteurs, de nombreux outils à cupules présentent des traces de chauffe (Cert, 2003). Les surfaces ont une coloration particulière (orangée pour les basaltes, grise pour les grès et dolomies) qui évoque sinon une chauffe des objets eux-mêmes du moins leur mise en contact avec des matériaux sortis du feu. Certains, comme le galet en microgranite (25) de la Capitelle du Broum ou l'outil à bec (76) en dolomie de la Roussignole 12, portent des fissures et des traces d'éclatement, liés à une chauffe intense. Dans l'inventaire, nous avons signalé toutes les pièces qui semblaient avoir subi une possible chauffe. Douze d'entre elles, dont huit proviennent de la Capitelle du Broum (seul site dont nous avons pu étudier la plupart des pièces), présentent des traces indubitables de chauffe. Parmi elles, cinq sont en grès, roche qui malgré sa propension à l'arénisation (qui peut d'ailleurs être accentuée par la chauffe) semble être la plus apte à conserver les traces d'un séjour proche d'une source de chaleur.

\section{LES TRACES MACROSCOPIQUES}

On distingue sur les outils à cupules cinq grandes plages d'utilisation, qui revêtent chacune un type de traces en particulier.

\section{La cupule}

Située plus ou moins au centre des faces principales de l'objet, elle se caractérise par une concentration d'impacts de percussion plus ou moins violents, de formes et de dimensions variables, sur une zone circulaire particulièrement bien circonscrite (fig. 11). Deux types d'impacts sont visibles dans ces cupules. Des entailles linéaires ou en étoile résultent d'une percussion lancée violente de type éclatement de matière; dans certains cas, on observe même deux, voire trois, stades d'éclatement violent à l'origine de véritables microcupules à l'intérieur des cupules principales (fig. 11, $\mathrm{n}^{\circ} 1$ ). Dans d'autres cas, de fins impacts circulaires de percussion lancée résultent d'un concassage plus léger et très régulier, mais tout aussi circonscrit; ils sont souvent continus entre la face active et le fond de la cupule (fig. 11, $\left.\mathrm{n}^{\circ} 2\right)$. 


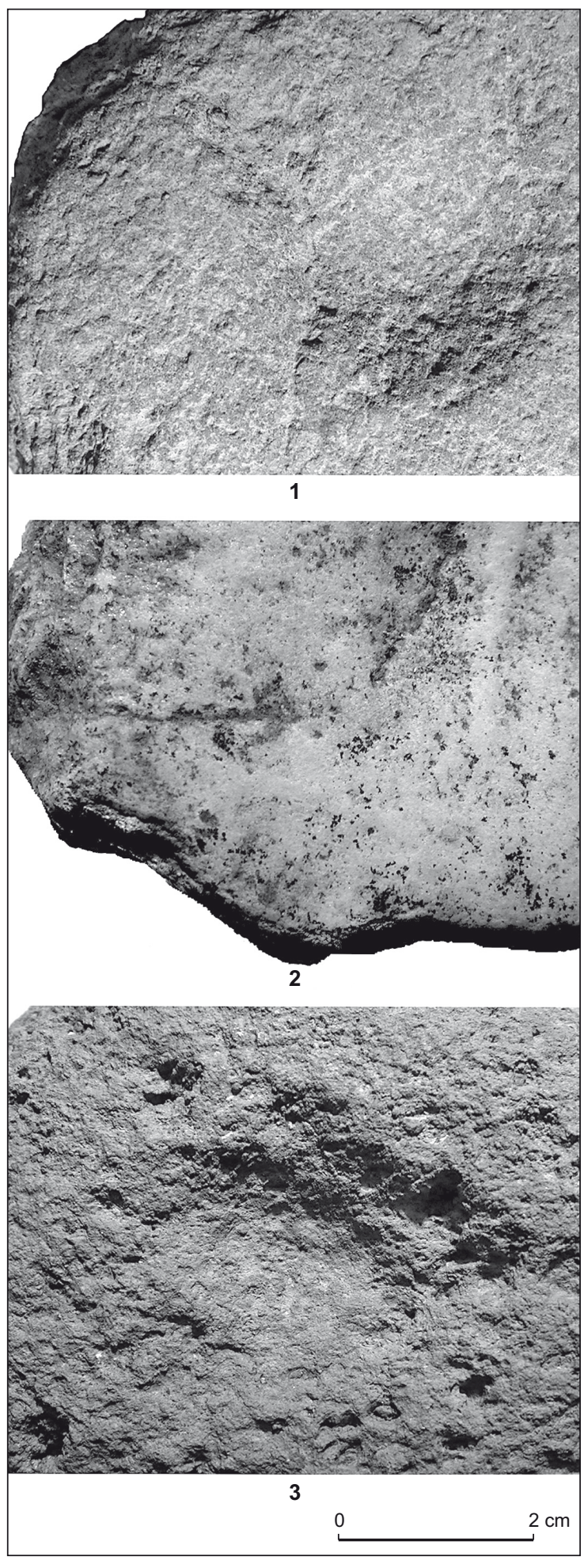

\section{La face principale}

Convexe à plano-convexe, elle présente généralement des traces de fine percussion assez régulière, associées à un
1 Fig. 11 - La Capitelle du Broum, cupules de percussion. 1, cupule avec entailles profondes successives due à un choc violent sur galet de basalte à peine utilisé; 2, cupule avec fins impacts de percussion au centre, on distingue encore les traces d'entaillage antérieures de la cupule; 3, lissage complet de la cupule due à une action de broyage d'une matière minérale dure de petite fraction, noter les traces d'entaillage antérieures (Clichés: C. Hamon).

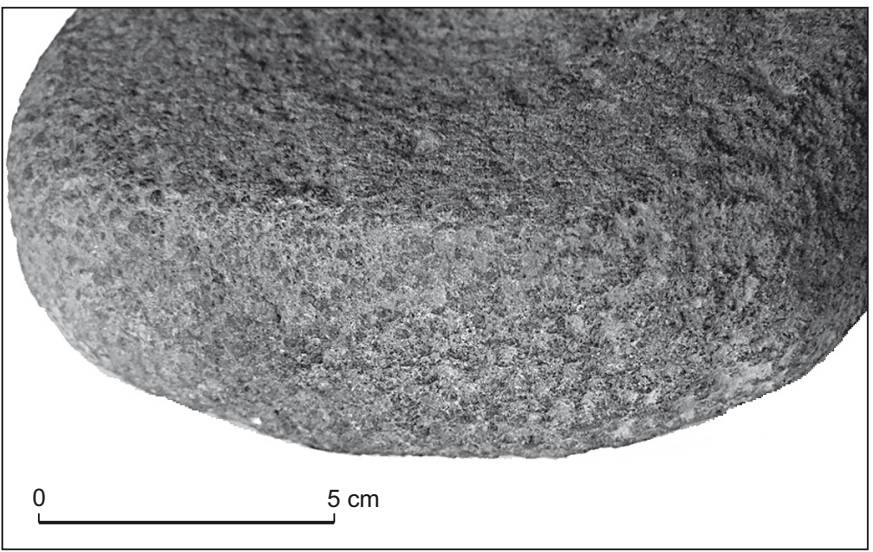

- Fig. 12 - Tranche finement percutée d'un outil de type 1 de Roque-Fenestre. Noter la continuité des impacts entre la tranche et la surface active et la création d'une véritable facette d'écrasement (Clichés: C. Hamon).

poli couvrant des aspérités. Une bande de lissage occupe fréquemment la périphérie des cupules: elle témoigne de l'usage intense de la cupule pour les activités de concassage et de broyage.

\section{Les arêtes}

Les surfaces actives des outils à cupules du type 3b présentent une retouche systématique et régulière liée, soit à la fabrication, soit à la préparation des zones d'utilisation.

\section{La tranche}

Le plus souvent porteuse de traces de façonnage par détachement d'éclats, elle revêt parfois de fins impacts de percussion régulière sur tout son pourtour (fig. 12).

\section{Les extrémités}

Associées ou non aux traces visibles sur la tranche, les impacts de percussion de l'extrémité sont plus grossiers et correspondent à un geste de percussion assez violent. 


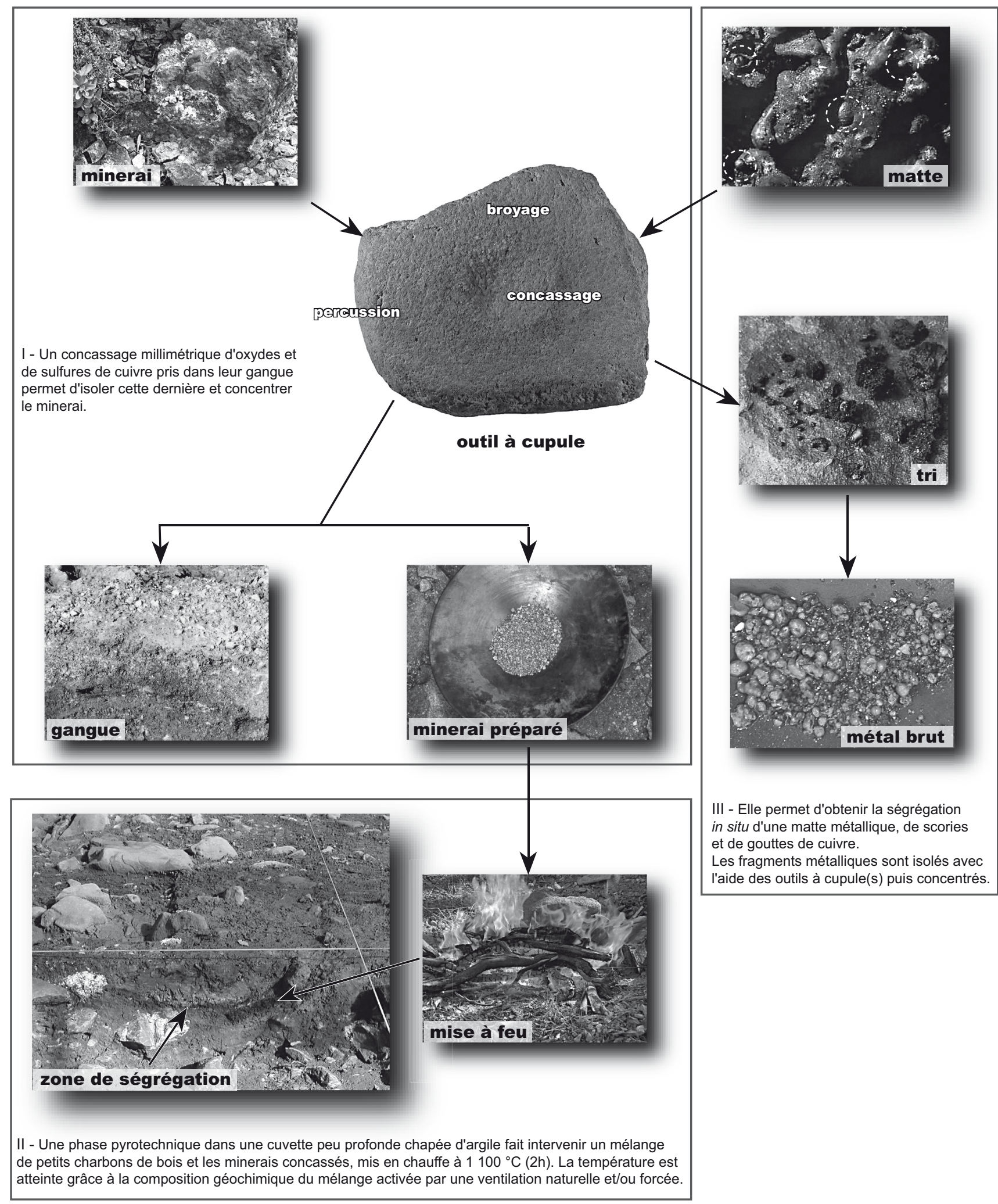

Fig. 13 - Rôle des outils à cupules dans la chaîne opératoire de la métallurgie du cuivre. Les outils à cupules assurent des fonctions multiples et sont employés à deux étapes principales de la chaîne opératoire de la métallurgie du cuivre. Ils sont très vraisemblablement utilisés en amont puis, en aval, de la métallurgie extractive du métal à partir des minerais de cuivre. En effet, ils servent à sélectionner et à concentrer dans un premier temps, pré-métallurgique, les particules minérales en les extrayant de leur gangue (fonction de percuteur puis de broyeur-concasseur), et, dans un second temps, post-métallurgique, à isoler les gouttes et la matte métallique, de la fraction scoriacée et des scories (concasseur et percuteur) (DAO: P. Ambert et C. Requirand). 

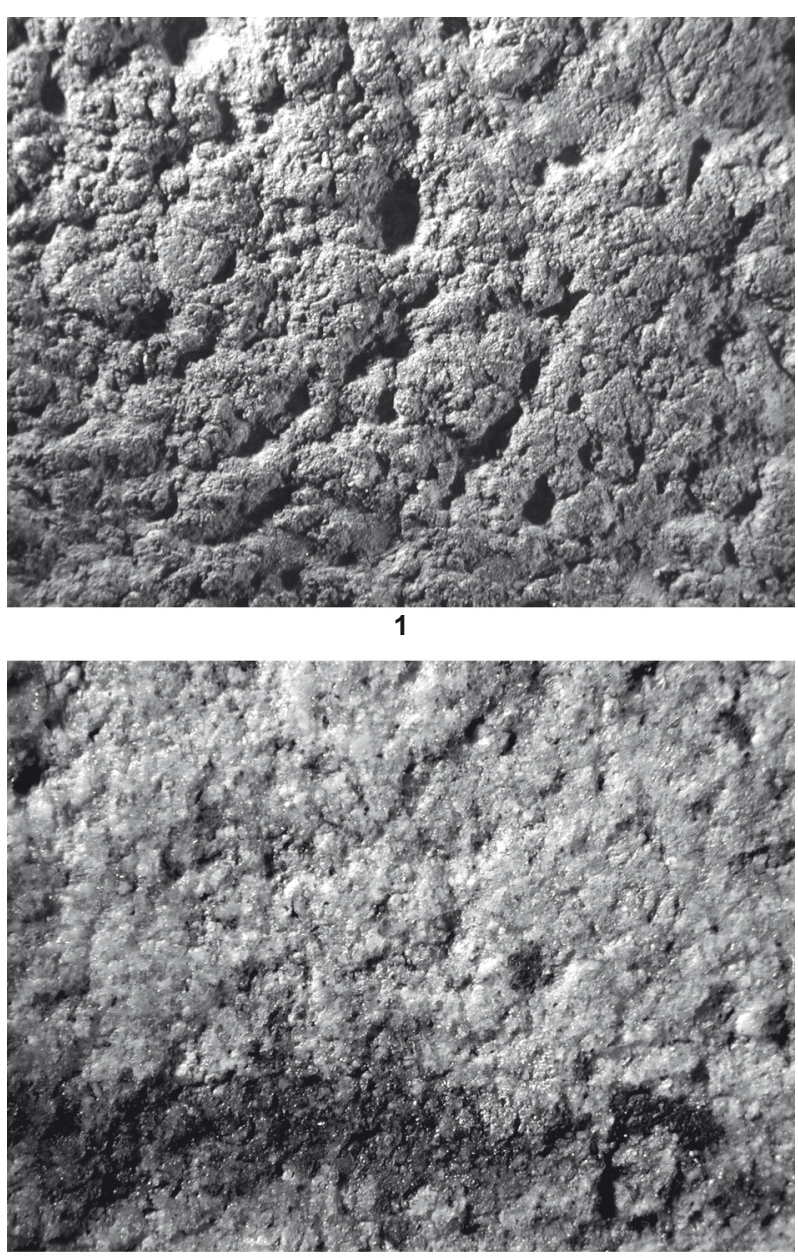

2

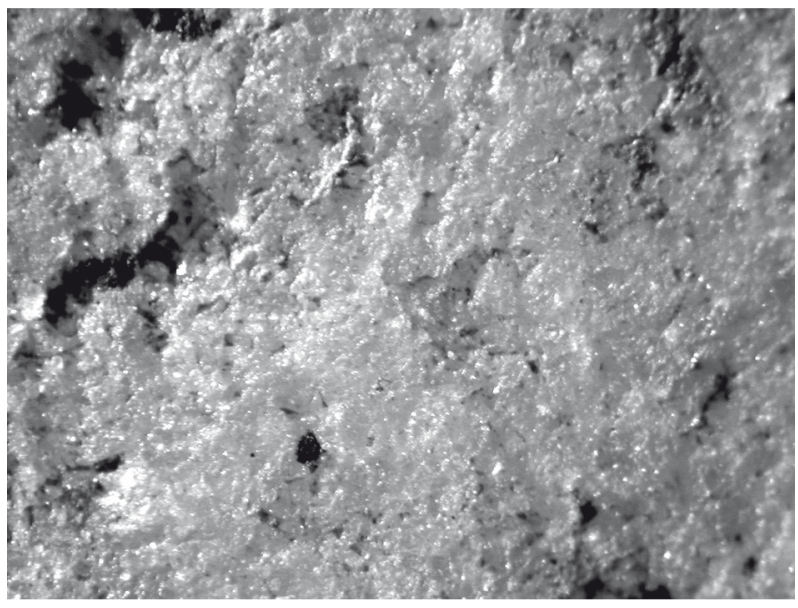

3

Fig. 14 - La Capitelle du Broum, observation à la loupe binoculaire des traces de percussion 1, impacts de percussion denses et fins au fond d'une cupule (x 5); 2, aspérités polies liées à un usage en broyage d'une matière minérale dure (x 10); 3, lissage complet de la surface due à une utilisation prolongée pour le broyage de petites fractions (poudre?) de matières minérales dures (x 30). (Clichés: C. Hamon)
La combinaison de la nature et de la localisation des traces permet de les associer à un geste particulier (fig. 13). Les cupules résultent donc d'un geste de concassage violent sur une matière dure et contondante: elles ont donc servi à fracturer, voire concasser, les gros morceaux de matière en fragments de plus petites dimensions (fig. 14, $\mathrm{n}^{\circ} 1$ ). Cette action peut être complétée, dans certains cas, par une percussion plus précise et plus fine à l'aide de l'extrémité des outils. La tranche et la face principale, pour leur part, semblent plutôt destinées à réduire la matière en petites fractions, respectivement par une fine percussion et par un broyage en percussion posée circulaire.

\section{LES TRACES MICROSCOPIQUES}

Un échantillon de 21 outils à cupules a fait l'objet d'une analyse optique des traces d'utilisation. Nous renvoyons le lecteur à d'autres travaux pour la méthodologie employée, qui consiste en une identification à la loupe binoculaire des déformations du relief de la matière (Hamon, 2006a). L'analyse des faces des outils à cupules indique une transformation de matière minérale dure. Les aspérités polies et lissées, tout comme les bandes de lissage sur le pourtour des cupules, présentent des grains bien individualisés et légèrement microfracturés (fig. 14, $\mathrm{n}^{\text {os }} 2$ et 3 ). Ceci évoque le broyage de fines particules minérales. Des stries transversales sont parfois visibles sur les faces principales des outils et indiquent le sens de broyage.

\section{LES RÉSIDUS}

En outre, deux types de résidus de matière ont été observés sur quelques exemplaires: des plaques de résidus accrochées aux plages arasées en relief et des résidus de matière cuivreuse oxydée situés au fond des impacts de percussion. Une cupule d'un des outils les plus caractéristiques de ces pièces de Roque-Fenestre porte des traces ponctuelles d'oxydes de cuivre (fig. $4, \mathrm{n}^{\circ} 1$ ). Il convient d'en conclure que ces cupules étaient le siège de chocs violents présidant à l'éclatement de roches minérales ou de produits métallurgiques durs et de petites tailles. La chauffe qui affecte la plupart des faces de ces pièces nous a fait préférer le second terme de cette alternative, même si son rôle dans la chaîne opératoire de transformation du minerai reste encore à définir.

Dans l'espoir de mieux comprendre la dévolution exacte des outils à cupules, nous avons entrepris un nettoyage soigneux et aussi peu agressif que possible de plusieurs de 
ces pièces, dont une partie de la surface est recouverte par des concrétions calcaires. C'est ainsi que plusieurs outils ont été nettoyés par microsons au Laboratoire de recherche des musées de France (Ambert et al., 2002), d'autres par jet d'eau sous pression au Laboratoire d'odontologie de Montpellier. Sur la dizaine d'outils présélectionnés, seuls trois, tous en basalte, ont livré des traces potentielles d'un héritage minéral ou métallurgique.

Les deux premiers, qui proviennent du site de RoqueFenestre, portent des traces dispersées de taches punctiformes, dont la couleur verte à reflet bleu indique clairement un oxyde de cuivre. Ces traces sont très présentes dans l'une des cupules de la pièce $\mathrm{n}^{\circ} 1$ de la figure 4 . Elles soulignent par leur densité le caractère dormant de cet outil de type la. Au contraire, la position de ces traces près de la pointe d'un outil de type $1 \mathrm{~b}$ renvoie incontestablement à une utilisation lancée laquelle, associée à la première, montre la dualité du geste lié à ce type d'outil. Néanmoins, pour l'heure, il n'est pas permis d'affirmer que ces traces d'oxydes proviennent du concassage d'une matière minérale ou, au contraire, d'un résidu métallurgique, postérieurement oxydé. Sur ce point essentiel, le seul indice qui puisse être évoqué est que la fosse, située à proximité immédiate de l'aire du four 19, si riche en débris de lingotières (37), n'a livré aucun de ces outils à cupules. Cet argument demeure insuffisant pour conclure.

Le troisième outil provient du site métallurgique chalcolithique du Valat Grand, situé dans le secteur nord de la commune de Cabrières (Laroche, 2004). Il s'agit, là encore, d'un outil de type $1 \mathrm{~b}$ (galet de basalte plat portant une seule cupule), qui porte des concrétions de couleur crème, laissant transparaître des traces vertes, dont la forme globulaire pourrait être simplement l'expression de la surface du support basaltique sous-jacent. Cette pièce a fait l'objet de plusieurs analyses par S. Rovira (Musée archéologique national de Madrid), qui ont porté sur divers points de la pièce, en particulier près de la cupule, afin de déterminer la présence de sels de cuivre.

S. Rovira a utilisé la technique de la spectrométrie par fluorescence aux rayons $\mathrm{X}$, au moyen d'un spectromètre Metorex XMET920 avec une source de Americio, et une fenêtre d'irradiation de $25 \mathrm{~mm}$ de diamètre. La configuration de l'appareil permet de détecter les éléments chimiques à partir du Ca (numérotation atomique 20). C'est ainsi que le support basaltique contient de petites proportions de Fe, Sr, Zr, Ba, et La.

Les spectres des deux faces de la pièce, et en particulier celui d'un échantillon pris dans la cupule, ne montrent pas de différence sensible (fig. 15). Les analyses réalisées sous les concrétions de couleur crème n'ont pas donné plus d'indices de présence de cuivre que les précédentes. Il en est de même au microscope, qui montre que le basalte a ponctuellement une teinte gris-vert, sans présence de malachite.

Malgré l'absence de preuve, il ne faudrait pas pour autant conclure que cet outil n'a pas servi à broyer le
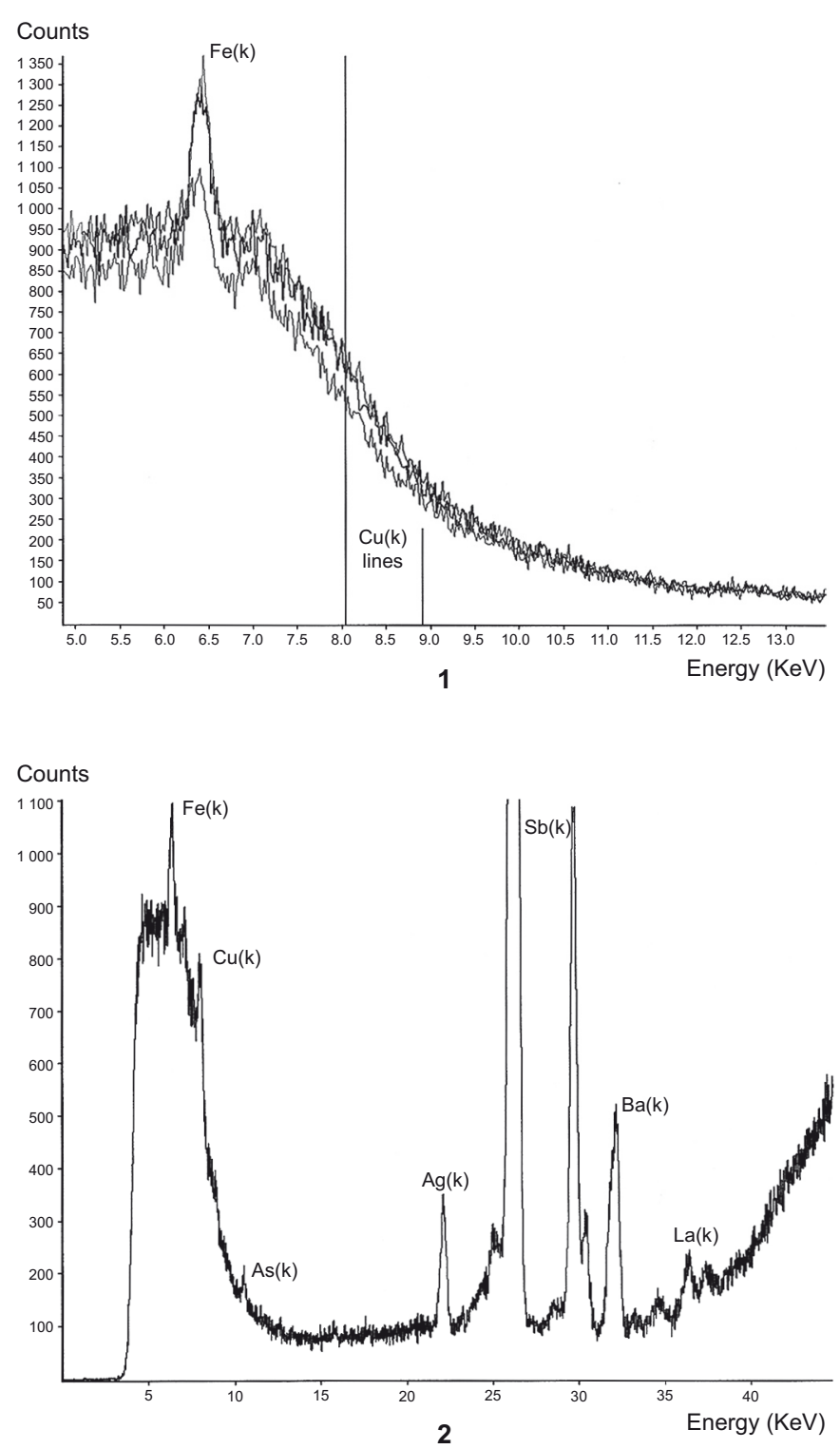

Fig. 15 - Analyse des prélèvements de matière en surface d'un galet à cupule de Valat Grand par spectrométrie par fluorescence aux rayons X. Ils ne contiennent pas de traces conservées de sels de cuivre (Diagrammes: S. Rovira). 
minerai de cuivre. En effet, les deux premières pièces indiquent le contraire. Mais deux paramètres au moins limitent la pertinence des analyses: d'une part, les sels de cuivre sont hydrosolubles et, au Valat Grand, comme dans les autres gisements de plein air du district de CabrièresPéret, la faible épaisseur des sédiments archéologiques a facilité le lessivage et l'altération des sels de cuivre; d'autre part, le spectromètre utilisé n'est peut-être pas assez performant pour détecter d'aussi petites quantités de cuivre. Aussi envisageons-nous ultérieurement de soumettre cette pièce à l'analyse des microtraces, technique déjà utilisée dans la caractérisation du contenu des produits alimentaires de récipients et des céramiques.

\section{GESTES ET UTILISATION}

\section{ENCHAÎNEMENT ET SÉQUENGES D'UTILISATION}

D’après la disposition des traces, il est possible de définir l'enchaînement des gestes et l'utilisation simultanée, consécutive ou encore alternative, des différentes parties d'un même objet. La séquence des gestes d'utilisation pour chaque grand type technofonctionnel est détaillée à partir de quelques exemples précis (fig. 13).

La chronologie de l'usage de chacune des parties des outils à cupules pourrait être la suivante :

- les cupules assurent l'éclatement initial d'un matériau dur en plusieurs fragments;

- les extrémités permettent de concasser les fragments obtenus précédemment;

- les faces et les tranches des outils permettent d'écraser ou de broyer la matière en particules encore plus petites selon un geste plus ou moins circulaire.

Les différentes usures indiquent une triple action d'éclatement d'un matériau contondant, dense et dur, puis de concassage en fractions plus réduites et enfin de broyage en fines particules.

Ces observations permettent de proposer une reconstitution de la fonction de ces objets qui sont dévolus à des opérations de réduction de fragments de matières dures contondantes en petites fractions. Chacune des faces des outils doubles présente systématiquement les mêmes traces d'utilisation. En conséquence, le type la serait en réalité le stade le plus avancé de l'usage d'outils du type 1b. À notre sens, le type 1b n'a en effet pas subi un façonnage initial plus élaboré que le type la. La régularité de l'épaisseur des outils, celle de la répartition des impacts sur les tranches et les faces, et l'écrasement homogène des extrémités corres- pondraient à un stade plus avancé de l'utilisation des outils du type 1a. Ces outils à cupules témoigneraient donc d'une durée et d'une intensité d'utilisation bien plus avancée que les outils de type $1 b$.

De même, l'utilisation ou non des outils à cupules comme percuteurs ne semble pas dépendre d'un type d'outils en particulier, mais plutôt des besoins spécifiques au moment de l'utilisation de chaque objet. Le geste de percussion sur la tranche ou l'extrémité de l'objet semble surtout venir en complément de l'usage principal réservé aux faces des outils à cupules. En effet, la régularité, la distribution et la forme des impacts indiquent que le geste n'était pas strictement équivalent pour tous les outils et toutes les faces d'une même pièce.

Les outils à cupules ne font l'objet d'aucun réemploi. Lorsque plusieurs faces des outils à cupules sont utilisées, elles revêtent des traces d'utilisation identiques. L'imbrication de traces d'utilisation différentes sur les outils à cupules démontre qu'elles correspondent à des gestes complémentaires visant à la même opération de transformation de la matière. Dans le cas des outils de type 1a, les cupules viennent entamer les surfaces actives piquetées et polies, tandis que, pour le type 2, le lissage vient masquer les impacts de percussion du fond de la cupule et de la surface active. Dans les deux cas, la disposition des traces évoque une alternance permanente entre un geste de concassage violent, un geste d'écrasement plus fin et un geste de broyage circulaire.

Dans le cas des dièdres (type 4), cet enchaînement ne semble pas valable. L'extrémité est très fortement percutée, mais ne semble pas directement liée à l'utilisation des faces, au point que l'on puisse envisager une réutilisation de ces objets en percuteur.

Le fonctionnement de l'ensemble des outils à cupules semble ainsi particulièrement homogène, avec une utilisation principale des faces à cupules et une utilisation «d'appoint» des tranches et des extrémités.

\section{POSITION ET CONDITIONS D'UTILISATION DES OBJETS}

Le fonctionnement des outils à cupules peut être appréhendé à partir de la morphologie des objets et de la localisation des différentes traces d'utilisation. Pour ces pièces, une utilisation percutante ou «répercutante» peut être envisagée. D’après des outils à cupules ethnographiques et préhistoriques utilisés pour le concassage de noix (de Beaune, 2000, p. 68), les traces d'utilisation seraient identiques entre les outils percutants et répercutants. À défaut de 
pouvoir résoudre la question de la position d'utilisation des outils à cupules, nous examinerons successivement les deux hypothèses fonctionnelles. Ces outils auraient tout à fait pu fonctionner deux par deux, l'un en position dormante, l'autre en position répercutante. Cette hypothèse nous semble la plus plausible. Elle aurait permis de piéger le matériau à concasser, au contraire d'un geste de broyage avec un outil oblong de type pilon-percuteur qui aurait provoqué une dispersion du produit de broyage plutôt que son écrasement. Sur le site de la Capitelle du Broum, quelques percuteurs en quartzite de forme subtriangulaire relativement étroite, portant des traces d'utilisation sur la pointe, ont été reconnus. Mais l'absence d'étude précise de ces objets ne permet pas de leur attribuer avec certitude la fonction de percuteur.

Les outils épais au dos convexe sont particulièrement adaptés à une prise en main. La présence de traces de poli gras consécutif d'une manipulation intense au dos de ces objets et l'émoussé qui caractérise les arêtes de leurs faces actives confirment l'utilisation de ces objets en percussion active, alternativement lancée et posée. Au contraire, les outils sur plaquettes s'avèrent à première vue mal adaptés pour une manipulation en percussion lancée active et pourraient avoir eu un usage répercutant à l'instar d'une enclume. Il semble pourtant difficile d'imaginer que ces outils aient fonctionné de façon différente. La forme convexe à plano-convexe des surfaces de broyage/concassage des outils à cupules se prête par ailleurs davantage à une utilisation en position percutante que répercutante. Les outils présentant des tranches et/ou des extrémités percutées n'ont pu fonctionner qu'en percussion lancée.

\section{UN MODE DE PRÉHENSION?}

À partir de l'observation des traces de percussion sur le pourtour des outils à cupules de type a, C. Cert émet l'hypothèse d'une utilisation ergonomique de la (ou les) cupule(s) (Cert, 2005). Celles qui ont la taille d'un doigt lui paraissent rendre la prise en main plus commode. L'auteur suggère également leur participation à un système d'emmanchement à l'identique de ceux parfois utilisés en Grande-Bretagne de concert avec les rainures des maillets de mineurs (Pickin, 1990). La comparaison vaut également avec ceux de Ross Island (O'Brien, 2004) à la différence près que, dans les exemplaires britanniques, l'ancrage de la cheville de blocage se fait sur un simple méplat ovoïde. Il ne s'agit apparemment jamais d'une cupule du type de celles de Cabrières-Péret.
Les cupules disposées symétriquement sur certains outils pourraient ainsi être interprétées comme des aménagements visant à faciliter la préhension et à maintenir la position des doigts lors de l'utilisation de l'outil en percuteur (Rahir, 1925; Espérou, 1993). Mais l'ensemble de la série démontre qu'aucun critère morphologique ou fonctionnel ne différencie les outils à deux cupules des outils à une ou trois cupules. Les cupules résulteraient donc bien toutes d'une utilisation en percussion lancée pour le concassage de différents matériaux.

\section{DURÉE ET INTENSITÉ D’UTILISATION}

Toute la gamme des durées et intensité d'utilisation est perceptible à travers l'observation des stigmates d'utilisation des outils à cupules. Des pièces, dont l'usage peut être qualifié d'opportuniste, sont présents dans les types $1 \mathrm{~b}$, $3 \mathrm{a}$ et peut-être 5. Elles portent les traces bien visibles d'un façonnage assez grossier et offrent des surfaces actives irrégulières peu utilisées. La cupule de percussion est, dans certains cas, le seul témoin de leur utilisation et aucune trace de percussion sur les tranches et aux extrémités n'est alors visible.

Les types 1b, 2 et 4 ont au contraire été intensément utilisés: ils associent un grand nombre de traces d'utilisation particulièrement denses et prononcées dans les trois cas. Leur utilisation a en outre entraîné la transformation de leur morphologie de départ, les impacts d'utilisation ayant le plus souvent masqués les traces initiales du façonnage.

\section{HYPOTHÈSE CONCERNANT LA FONGTION DES OUTILS À GUPULES DU DISTRICT DE CABRIÈRES-PÉRET}

À la lumière de toutes ces observations, deux fonctions peuvent être proposées pour les outils à cupules: le concassage du minerai ou celui des scories de cuivre. Dans le premier cas, les outils à cupules seraient utilisés pour dégager les fragments de minerai de cuivre de leur gangue et des éventuels fragments de roches ou de filons de quartz associés. Dans le second cas, le concassage viserait à récupérer les billes de cuivre incluses dans les scories. La violence des impacts visibles dans les cupules plaiderait plutôt pour la première hypothèse, tandis que la finesse des impacts observés sur les tranches et les faces des outils à cupules plaiderait plutôt pour la seconde. L'utilisation successive de ces outils pour les deux opérations ne doit pas 
non plus être écartée. Récemment, la fouille de sauvetage de la fosse 33 du site de Valat Grand à Cabrières nous a fourni, avec un ensemble céramique de grands vases à cordons très caractéristique du Néolithique final-Chalcolithique local, un outil à cupules en basalte associé à un dépôt pluricentimétrique de sables cuivreux et ferrifères. Il s'agit d'un rejet de scories concassées, sans doute expurgées des gouttes de cuivre qui pouvaient y être incluses au terme de la métallurgie extractive. Les analyses géochimiques réalisées montrent qu'il s'agit bien de scories altérées, contenant une forte présence de cuivre (fig. 15). En outre, la localisation quasi exclusive des outils à cupules dans les sites métallurgiques, et leur cohabitation avec de fins broyats de scories déjà attestée à Roque-Fenestre (Ambert et al., 1984) plaident en faveur de leur utilisation préférentielle dans le concassage et le tri des résidus métallurgiques. Sans doute n'est-elle pas exclusive, mais les exemples préhistoriques et surtout ethnographiques rapportés infra (p. 201) renforcent cette conviction, qui fut d'ailleurs la première choisie pour les objets de Cabrières-Péret.

\section{APPROCHES ARCHÉOLOGIQUES ET ETHNOGRAPHIQUE DE LA FONCTION DES OUTILS À CUPULES}

\section{OUTILS À GUPULES, ETHNOGRAPHIE ET PRÉHISTOIRE}

Les outils à cupules existent dès le Paléolithique, comme l'attestent plusieurs exemplaires d'Isturitz (de Beaune, 2000, fig. 4 ; fig. $16, \mathrm{n}^{\circ} 1$ ), bien que les cupules présentent un contour moins régulier et soient assez rarement représentées sur les deux faces planes de l'objet.

Plusieurs observations rapportées par S. de Beaune dans un premier article de 1989, puis dans un ouvrage plus récent (de Beaune, 1989 et 2000), nous ont semblé particulièrement probantes. Parmi les objets étudiés, la meilleure correspondance avec les galets à cupules est à mettre au compte de ceux de type 1 , les mieux représentés dans le district de Cabrières-Péret. Dans le cas des pièces collectées dans les études ethnographiques, les quelques objets illustrés sont approchants mais non totalement identiques.

Morphologiquement, ce sont les outils des Sambaquis brésiliens (de Beaune, 1989, fig. 4, $\mathrm{n}^{\text {os }}$ 2, 4, 6) qui supportent le mieux la comparaison avec les objets découverts à Cabrières-Péret (de Beaune, 1989). Appelés quebra-cocôs, ils sont le résultat d'une percussion lancée beaucoup plus irré- gulière que celle affectant les objets chalcolithiques (fig. 16, $\mathrm{n}^{\circ} 2$ ). Nous ne possédons malheureusement que peu d'informations relatives à leur épaisseur et à leur pétrographie. Si l'un des quebra-cocôs possède une cupule sur chaque face (de Beaune, 1989, fig. 4, $\mathrm{n}^{\circ} 2$ ), aucun d'entre eux ne présente de polissage des faces ou de stigmates d'une percussion périphérique sur leur tranche.

C'est ainsi que notre collègue considère en toute logique ces objets comme des enclumes et en aucun cas comme des percuteurs (tabl. I et II). Le type de percussion qui affecte les quebra-cocôs est punctiforme, ce qui serait l'indice d'un outil servant au concassage de «noyaux, noix, graines dures» (tabl. I). Leur utilisation répétée permettait d'obtenir «une cupule irrégulière» (tabl. II), alors que «sa ou ses faces planes ou convexes, avec cupule centrale ou latérale irrégulière » renvoie à des enclumes de type quebracocô ou kulki (tabl. II).

Aussi la ressemblance avec les galets à cupules de métallurgiste de type Cabrières, présentant des faces planes souvent abrasées, des cupules régulières, et des pourtours façonnés par les chocs, n'est que très superficielle et ne résiste pas à une analyse approfondie. Néanmoins, le détour par le travail de S. de Beaune nous est apparu d'autant plus fructueux qu'il assimile le percuteur à «un galet ou pierre de forme régulière sphérique ou ovoïde» ce qui, après l'existence des cupules, est la caractéristique la plus accusée des outils de la région de Cabrières. À ce terme, l'outil de type la qui nous intéresse ici pourrait cumuler les fonctions de percuteur et d'enclume, alors que certains de ces outils, regroupés initialement sous le seul terme générique de galet à cupules, pourraient être seulement tantôt l'un, tantôt l'autre.

Ils sont également présents au Mésolithique: dans une note, A. Becker, M. Toussaint et G. Lawarrée présentent une carte de répartition des outils de cette époque, laquelle associe les îles Britanniques, le littoral allemand et la Scandinavie (Becker et al., 1994). La France et le sud de l'Europe en sont en revanche totalement démunis. Ces auteurs proposent que le façonnement des cupules soit antérieur à leur utilisation (fig. 16, nos 3 et 4).

Aussi, sans pousser les recherches au-delà, il convient de se rendre à l'évidence que les objets à cupules ne sont pas spécifiques aux pratiques métallurgiques. Celles-ci utilisent un objet dont l'efficacité dans le concassage extractif d'éléments durs et de petite taille (ici minéral et/ou métallurgique) a depuis bien longtemps fait ses preuves. Une fois encore, il convient de conclure que l'utilisation des outils à cupules pour les opérations métallurgiques dans le district 

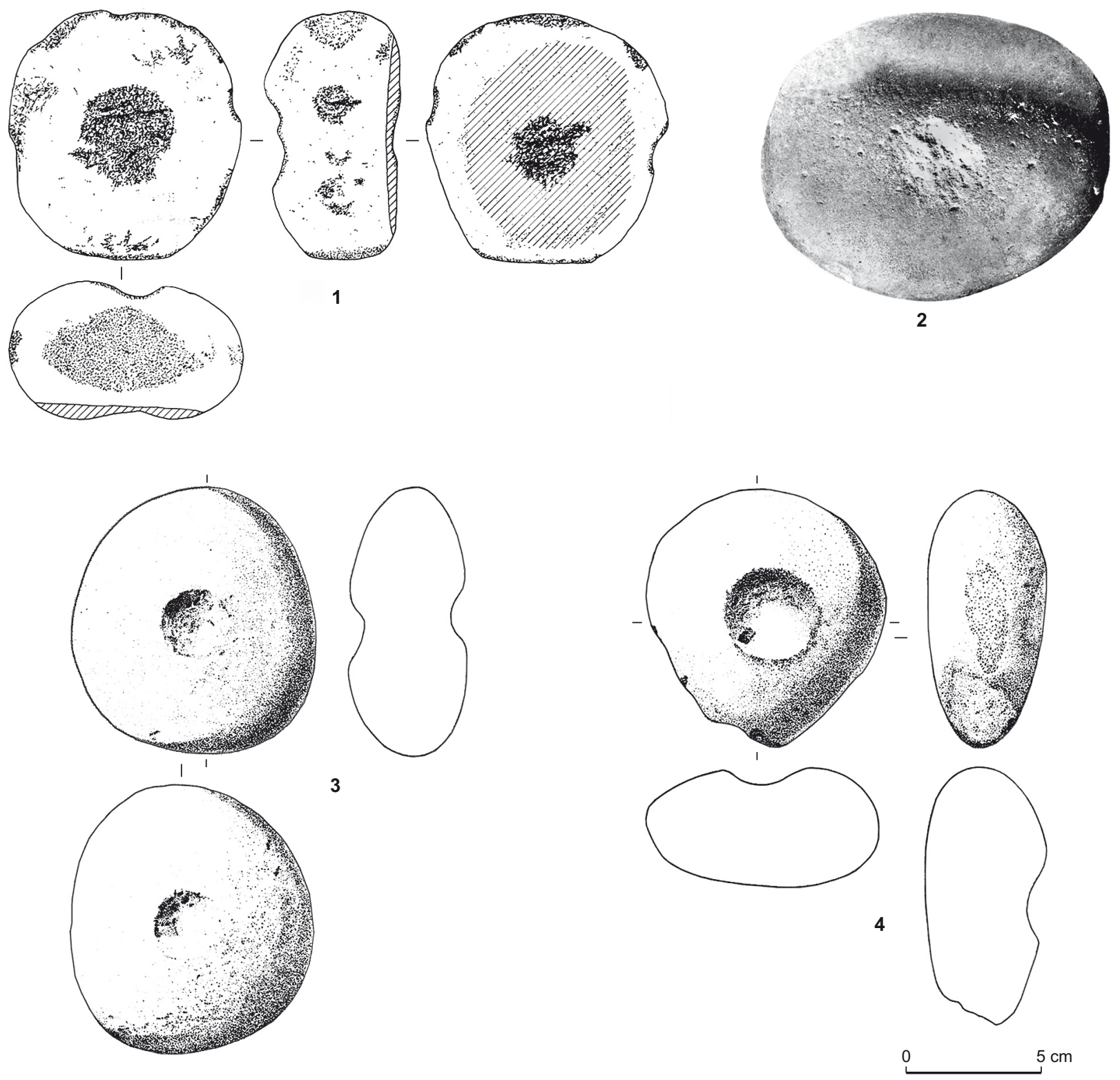

Fig. 16 - Sélection d'outils à cupules provenant de sites paléolithiques: 1 et 2, galet à cupule d'Isturitz, gravettien et mésolithique (d'après de Beaune, 2000, fig. 20 et de Beaune, 1989, fig. $2 n^{\circ}$ 4); 3, Station Leduc; 4, la Roche aux Faucons/pente, série Lequeux (d'après A. Becker et al., 1994).

de Cabrières-Péret constitue une adaptation fonctionnelle efficace, plutôt qu'une réelle innovation technique. Ici, l'outil s'est avéré indispensable dans le tri de matières dures de petite taille liées à la métallurgie des sulfures de cuivre. Dans un premier temps, il a sans doute permis la récupération des fractions de minerai de bonne qualité, puis, dans un second temps, l'extraction et l'isolement des gouttes de cuivre et l'élimination des scories siliceuses qui les contenaient.

\section{LES OUTILS À GUPULES DE MÉTALLURGISTES EUROPÉENS}

\section{LES OUTILS À CUPULES DU MIDI DE LA FRANCE}

Depuis le recensement fait par l'un d'entre nous (Ambert, 1992), si le nombre des sites ayant fourni des outils à cupules n'a que très modestement augmenté, tous sans exceptions ont révélé des pratiques métallurgiques in situ. 


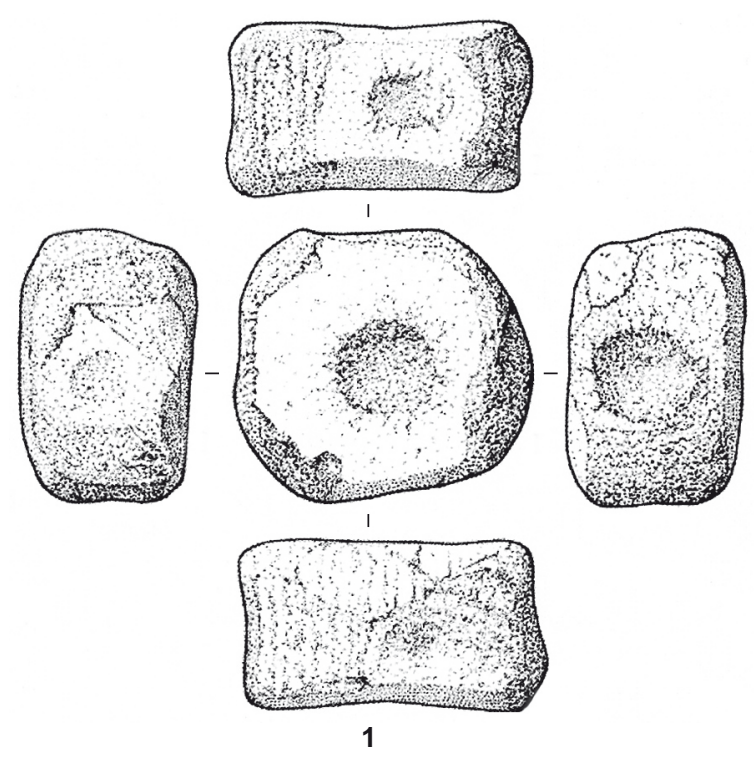

Fig. 17 - Sélection d'outils à cupule(s) provenant de sites français: 1, la Vayssonnié, fosse A 62, (Rosières, Tarn), métabasite (d'après Y. Tchérémissinoff, 2006); 2, Cabane des Clausis, Saint-Véran (Hautes-Alpes), serpentinite (d'après H. Barge, 1996).

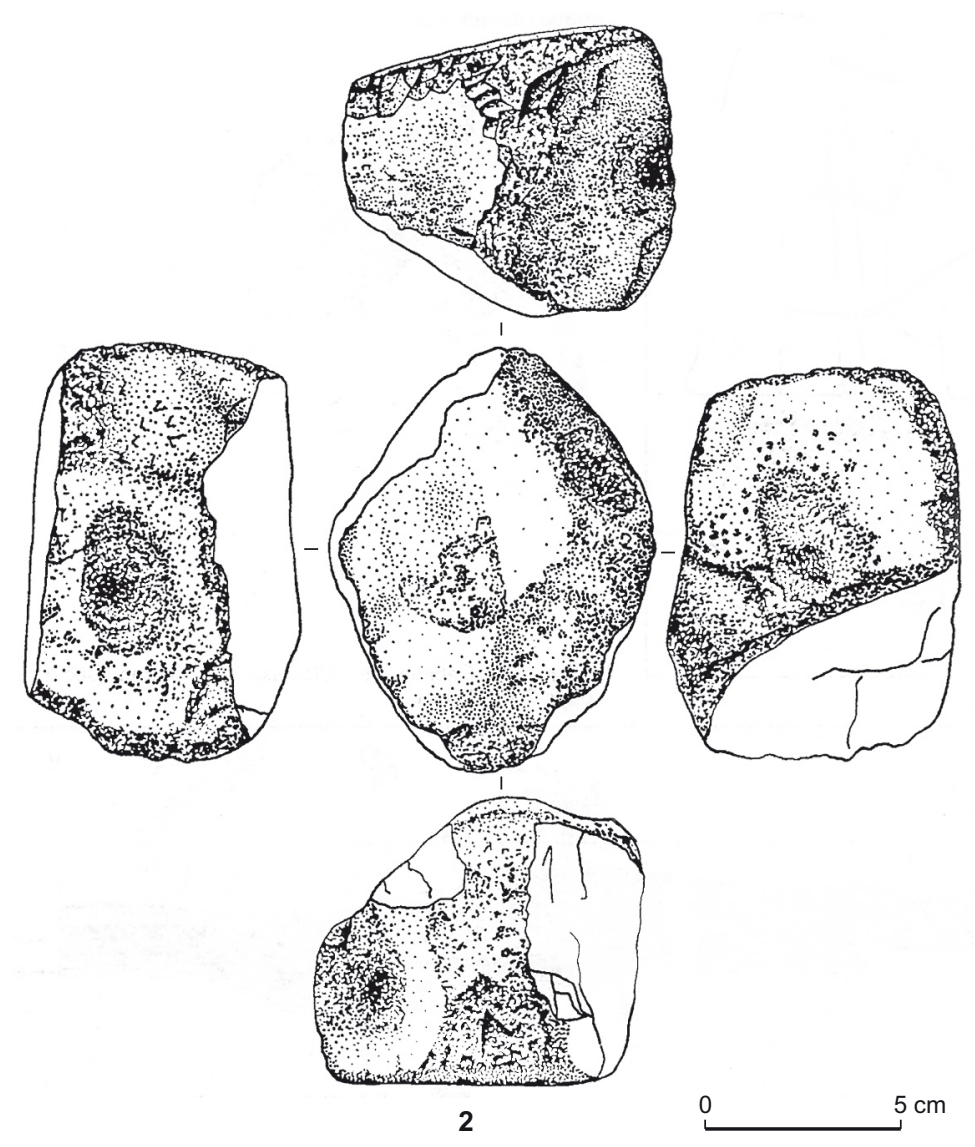

Un site inédit, qui mérite vérification, aurait été trouvé lors des travaux de l'A 75, près de Millau (Aveyron), non loin du gisement du Jas del Biau. Un galet à cupules proviendrait de l'une des fosses inventoriée au lieu-dit Brocuéjouls. Malgré des demandes réitérées nous n'avons pas pu authentifier la pièce, prétendument associée à des scories, ce qui ne saurait a priori étonner, compte tenu de la proximité d'un karst à baryte cuprifère (Aubague et al., 1977).

Récemment, les recherches de Y. Tchérémissinof (2006) menées dans le cadre du contournement de Carmaux ont fourni un galet à cupules avec quelques indicateurs métallurgiques, dans un contexte chalcolithique bien établi (GrN 29160: $4020 \pm 20$ BP, soit 2577-2478 cal. BC).

À cette courte liste, il convient d'ajouter les sites inclus dans la liste de 1992: Ouveillan (Aude), et avec moins de certitude Tribes à Bassan (Hérault). En revanche, les outils de type Puech Arnaud (Servian, Hérault), comme celui de Cerro Murciano (Andalousie, Espagne) (cité par C. Cert, 2002), doivent être à notre avis assimilés l'un comme l'autre à des systèmes d'emmanchement comme ceux présentés par Pickin (1990) en Grande-Bretagne. 


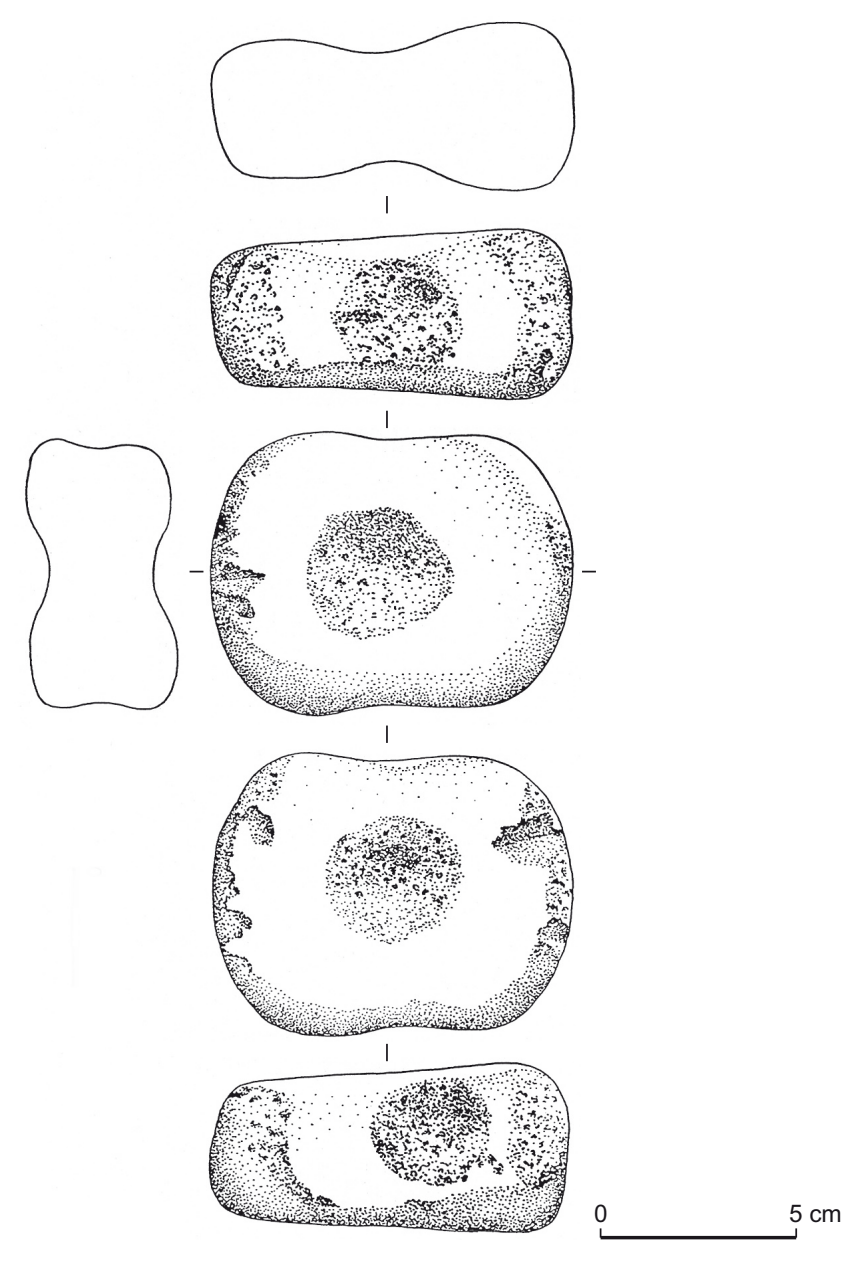

Fig. 18 - Les Grès, Collobrières (Var), galet de quartzite (d'après H. Barge, 1998).

L'enceinte chalcolithique de Boussargues, située à une vingtaine de kilomètres au nord-est de Cabrières, gisement où la production métallurgique est absente et les objets métalliques indigents, a fourni plusieurs outils en pierre portant des cupules (Colomer et al., 1990, fig. 60, $\mathrm{n}^{\text {os }} 1,2,5$ ). Les auteurs les ont dénommé molettes, terme qui pourrait très bien être utilisé pour de nombreux outils à cupules de Cabrières-Péret. Ici leur relation à la métallurgie reste à démontrer.

\section{QUELQUES OUTILS À GUPULES ASSOCIÉS À LA MÉTALLURGIE DU DOMAINE ALPIN}

L'attribution du site de Brixlegg (Autriche) à la première moitié du IV millénaire (Bartheleim et al., 2003) ne saurait réellement étonner, compte tenu de l'ancienneté de la métallurgie des cultures alpines de Pfynn ou de Mondsee (Strahm, 1994 et 2005). Dans un article antérieur concernant Brixlegg figurent deux galets plats à double cupule typiques (Reiser, Schrattenthaler, 1998-1999). Le premier est subcirculaire, plat à double cupule (fig. 19, $\mathrm{n}^{\circ} 1$ ), en amphibolite, très semblable à l'un des exemplaires de Roque-Fenestre (fig. 2, $\mathrm{n}^{\circ}$ 7). Le second, en gabbro (fig. 19, $\mathrm{n}^{\circ} 3$ ), se rapproche lui aussi d'un autre exemplaire de Roque-Fenestre (fig. 2, $\mathrm{n}^{\circ} 3$ ). Pourtant, l'une des deux cupules est nettement plus petite que l'autre et porte de surcroît, sur chacune de ses deux tranches, deux encoches latérales d'emmanchement, d'un type souvent utilisé sur les maillets de mineurs en Grande-Bretagne (Pickin, 1990; O’Brien, 2004). Cette caractéristique est très intéressante puisqu'elle peut matérialiser l'utilisation des cupules dans un système de ligature d'un manche ou bien jouer pro parte un rôle pour faciliter la préhension dans l'utilisation lancée du galet à cupules. En revanche, les seuls outils de Ross Island (appelés grinding stones) (O’Brien, 2004) possédant des cavités cupuliformes sont souvent très épais, voire sont de véritables meules. Enfin, il convient d'ajouter que l'étude des galets en pierre dure d'Arbon-Bleiche (canton de Thurgau, Suisse), en l'absence de toute cupule, a révélé sur 123 d'entre eux des traces de cuivre métallique, parfois de taille importante (puisqu'il peut s'agir de plaques de plusieurs centimètres) (Capitani et al., 2002). Les analyses ont révélé une composition géochimique $(\mathrm{Cu}, \mathrm{Ni}, \mathrm{Zn}, \mathrm{Pb}$ ) permettant de suspecter une métallurgie de haut niveau technologique à base de sulfures de cuivre, voire de chalcopyrite.

Plus au sud, dans le Tyrol Italien, on connaît depuis longtemps les outils massifs, à cupules, signalés par Preuschen (1973). Ils sont beaucoup plus proches des enclumes à cupule sommitale que des formes précédentes. Dans le reste de l'Italie, les pièces qui nous intéressent ne semblent en revanche pas avoir suscité d'intérêt, bien qu'il soit vraisemblable qu'elles existent. Elles n'ont néanmoins pas été signalées dans les aires de métallurgistes pourtant abondantes du sud des Alpes (Ambert, 1997).

\section{LE DOMAINE HISPANIQUE}

Les outils à cupules y sont particulièrement nombreux et la liste que nous donnons ci-après ne peut être considérée qu'à titre indicatif. Il existe en outre, à la périphérie des mines, des blocs, parfois métriques, portant de très nombreuses cupules (Domergue, 1990). Il s'agit ici d'un outil quelque peu différent, sans doute réservé à une première 

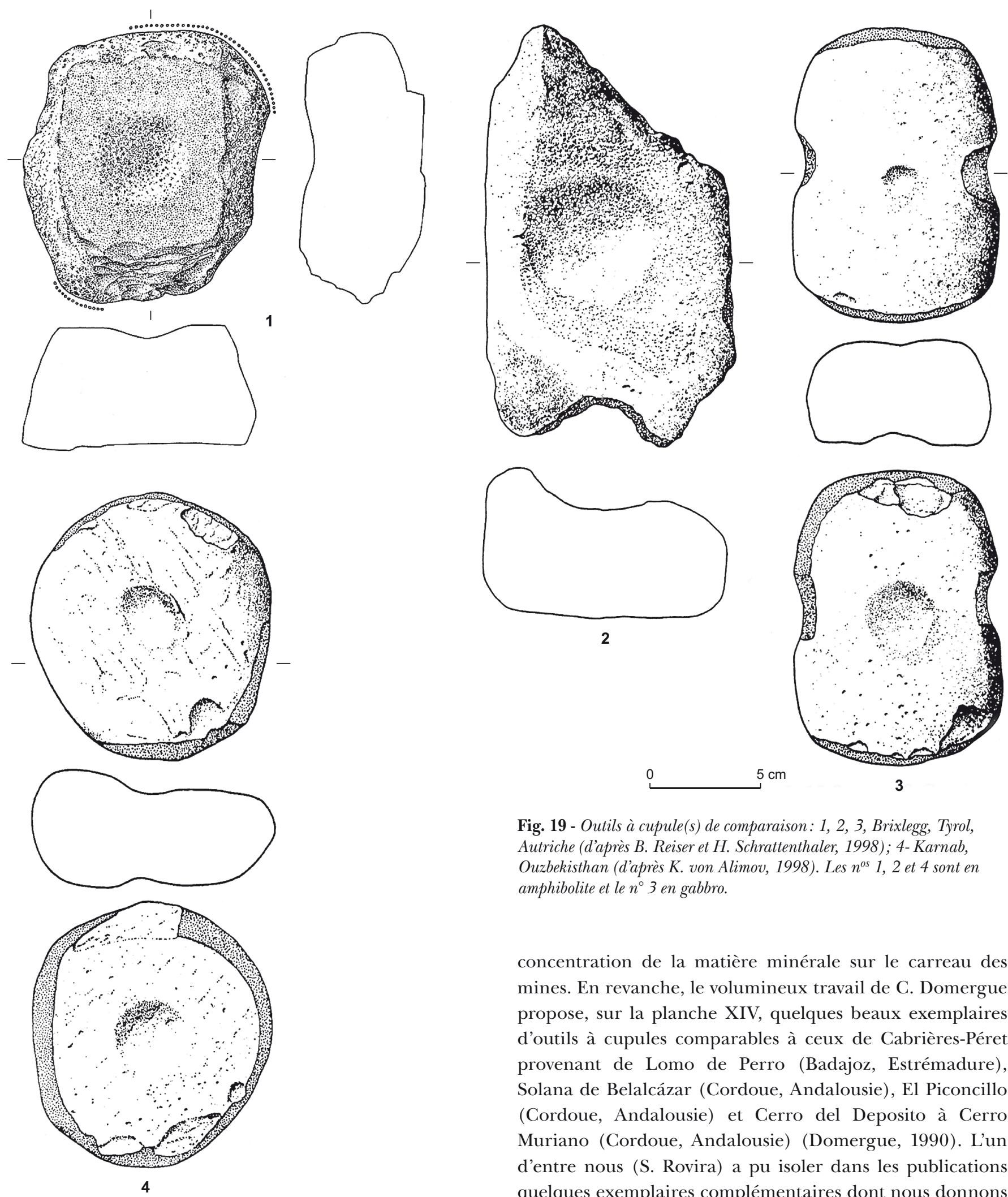

Fig. 19 - Outils à cupule(s) de comparaison: 1, 2, 3, Brixlegg, Tyrol, Autriche (d'après B. Reiser et H. Schrattenthaler, 1998); 4- Karnab, Ouzbekisthan (d'après K. von Alimov, 1998). Les $n^{\text {os }} 1$, 2 et 4 sont en amphibolite et le $n^{\circ} 3$ en gabbro.

concentration de la matière minérale sur le carreau des mines. En revanche, le volumineux travail de C. Domergue propose, sur la planche XIV, quelques beaux exemplaires d'outils à cupules comparables à ceux de Cabrières-Péret provenant de Lomo de Perro (Badajoz, Estrémadure), Solana de Belalcázar (Cordoue, Andalousie), El Piconcillo (Cordoue, Andalousie) et Cerro del Deposito à Cerro Muriano (Cordoue, Andalousie) (Domergue, 1990). L'un d'entre nous (S. Rovira) a pu isoler dans les publications quelques exemplaires complémentaires dont nous donnons la liste pour information: 

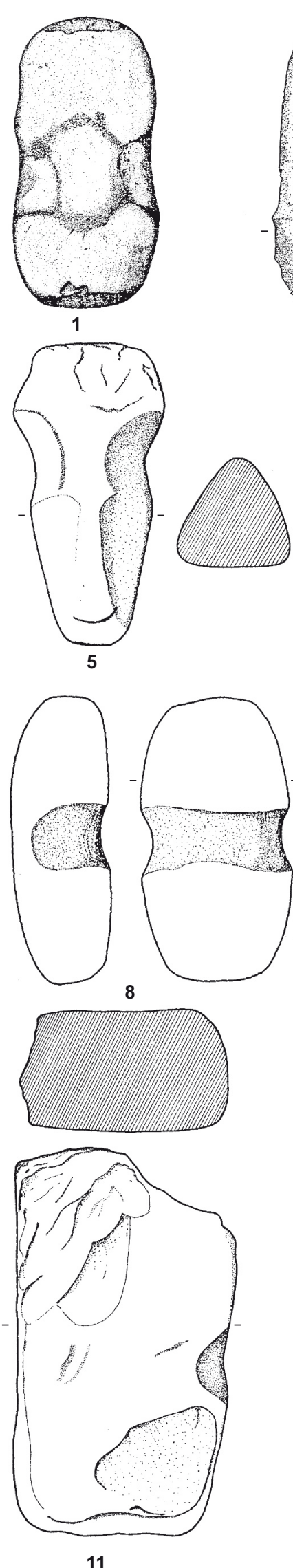
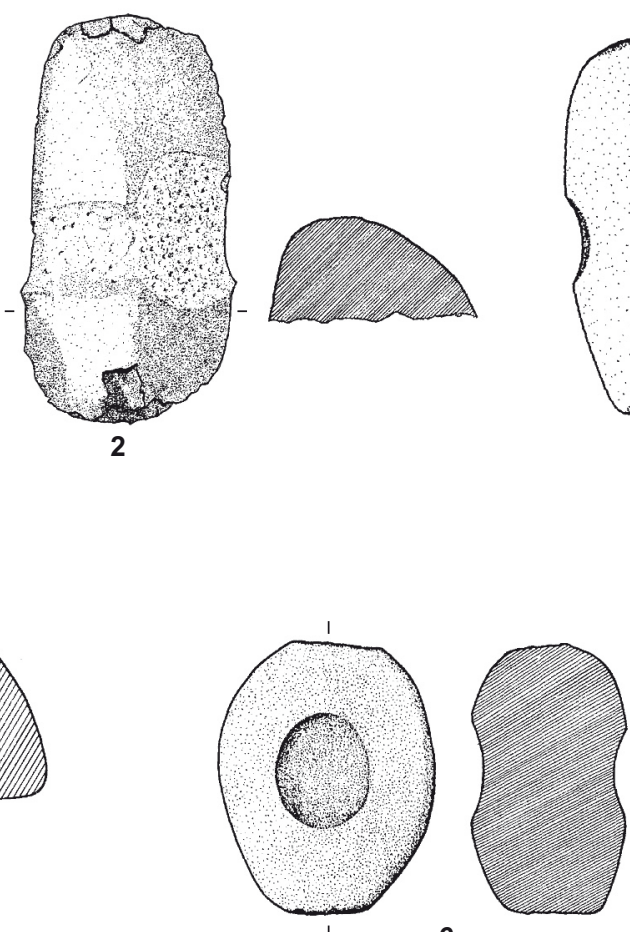

6
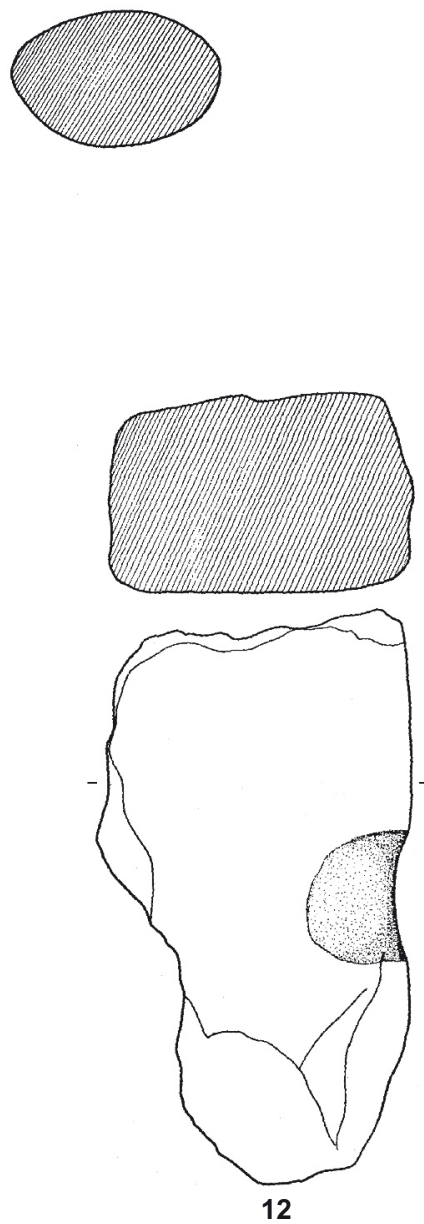
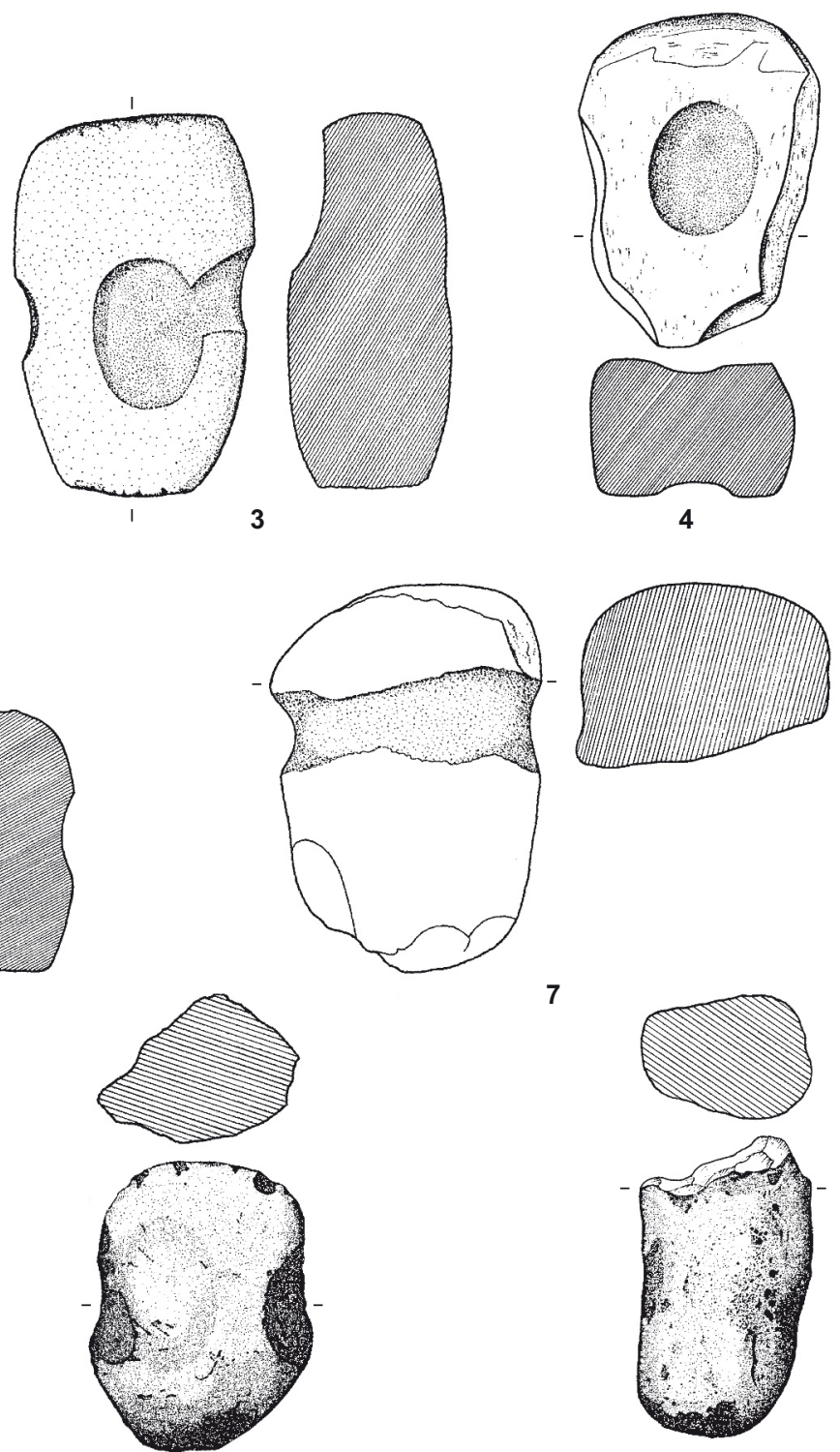

10

Fig. 20 - Outils à cupules et percuteurs en pierre de la mine d'El Aramo (Asturies, Espagne), grès et quartzite (d'après M.A. de Blas Cortina, 2005). 
- mines El Aramo (Asturies): plusieurs outils à cupules double ou simple, appelés percuteurs; âge du Bronze (Blas Cortina, 2005, fig. 2) (fig. 20);

- Cabezo Juré (Alosno, Huelva); Chalcolithique (Saez et al., 2004);

- La Loba (Fuenteovejuna, Cordoba), Chalcolithique Peraleda de Zaucejo (Badajoz) et mine de Chinflon (Zalamea la Real, Huelva), Bronze final (Hunt, 2003)

- La Minilla (Granja de Torrehermosa, Badajoz); Chalcolithique (Dominguez, 2001);

- Cerrico de Santa Ana y El Portichuelo (Jumilla, Murcia); âge du Bronze ancien-moyen (Simon et al., 1999);

- Ladera de San Anton (Orihuela, Alicante) ; âge du Bronze (Simon, 1998);

- nombreux exemplaires dans la Sierra de Cordoba; Chalcolithique-Bronze (?); ainsi que de nombreux exemplaires dans le monde argarique du sud-est de l'Espagne (Siret, 1887).

\section{QUELQUES OUTILS À CUPULES DU PROCHE- ET DU MOYEN-ORIENT}

Les outils à cupules existent également dans le monde méditerranéen (Chypre, Weisgerber, 1981), mais aussi dans le Proche- et le Moyen-Orient (Hauptman, com. orale). Partout ce sont de bons marqueurs des débuts de la métallurgie. C'est ainsi qu'un très bel exemplaire à une seule cupule (fig. 19, $\mathrm{n}^{\circ} 4$ ) a été découvert en compagnie de plusieurs maillets (dont la plupart n'ont pas de gorge) dans le complexe minier-métallurgique de Karbad à l'ouest de Samarkande (Alimov et al., 1998).

En Anatolie, et en particulier dans le district de Murgul, on signale des outils à deux cupules opposées sur des fragments de roches à face plane (type 1) et, comme en Espagne, des blocs beaucoup plus volumineux de type enclume portant sur l'une et parfois l'autre face de nombreuses dépressions cupuliformes (Wagner et al., 2000). Des documents tout à fait superposables à ces dernières sont légions dans certains secteurs miniers d'Espagne (Domergue, 1990).
Les outils à cupules du district minier-métallurgique de Cabrières-Péret sont donc sans nul doute des outils dévolus à la chaîne opératoire conduisant du minerai de cuivre aux objets métalliques à base de cuivre. Leur présence, désormais bien connue dans d'autres sites métallurgiques français (Saint-Véran, Hautes-Alpes), autrichien (Brixlegg) et espagnol (Cabézo Juré), ne se dément pas dans le Procheet le Moyen-Orient, soulignant bien le rôle déterminant auquel ils ont pris part dans cette première métallurgie.

Ces objets utilisables pour concasser, moudre et, in fine, trier des particules dures et de petite taille semblent tout à fait adaptés pour l'extraction des gouttes de cuivre de la matte scoriacée qui les contient au terme de la phase métallurgique proprement dite. Ils ont pu en amont participer à la préparation des minerais. À la Capitelle du Broum, la découverte de nombreuses gouttes de cuivre isolées, comme la conservation de microgouttes au sein des scories, suppose un travail de cet ordre, réalisé au moyen des galets à cupules découverts dans le mobilier du site.

La nature des traces d'utilisation et leur localisation sur les outils à cupules rendent compte d'un geste parfaitement maîtrisé et d'une régularité dans les actions effectuées. Il s'agit d'un outillage spécialisé, dédié aux activités de transformation du minerai en métal. La mise en place d'un protocole expérimental intégrant le concassage et le broyage à la fois du tout venant d'extraction, du minerai de cuivre et des scories de cuivre devrait permettre de mieux cerner à quelle(s) étape(s) exacte(s) de la chaîne opératoire de transformation du minerai interviennent les outils à cupules.

\section{Remerciements}

Nous tenons à remercier ici toutes les personnes qui ont contribué depuis près de trente ans à l'étude du district minier de Cabrières-Péret. Nous aurons une pensée particulière pour notre ami Denis Dainat $(\dagger)$, pour Albert Colomer, Bernard Beaumes et Claude Requirand à qui l'on doit les photographies et une partie des illustrations de cette étude. C. Hamon a bénéficié d'une allocation de recherche postdoctorale de la région Île-de-France pour la publication de ce travail. 
ANNEXE 1 - Inventaire des 116 outils à cupules analysés du district minier de Cabrières-Péret

\begin{tabular}{|c|c|c|c|c|c|c|c|c|c|c|}
\hline $\begin{array}{l}\mathbf{N}^{\circ} \\
\text { inv. }\end{array}$ & Site & Type & Chauffe & Cupule & Forme & Section & Techno & Face & Tranche & Extrémités \\
\hline 1 & ROF & $1 \mathrm{a}$ & & double & ovoïde & rectangulaire & & impacts et poli couvrant & $\begin{array}{c}\text { percussion } \\
\text { régulière, dense }\end{array}$ & \\
\hline 2 & ROF & $1 \mathrm{a}$ & & & & & & & & \\
\hline 3 & ROF & $1 \mathrm{a}$ & & & & & & & & \\
\hline 4 & ROF & 1 & & & & & & & & \\
\hline 5 & ROF & $1 \mathrm{a}$ & & & & & & & & \\
\hline 6 & ROF & $1 \mathrm{a}$ & & & & & & & & \\
\hline 7 & ROF & $1 a$ & & & & & & & & \\
\hline 8 & LCB & $1 \mathrm{a}$ & & & & & & & & \\
\hline 9 & PF 448 & $1 \mathrm{a}$ & & double & trapézoïdale & $\begin{array}{c}\text { triangulaire, } \\
\text { convexe }\end{array}$ & & $\begin{array}{l}\text { impacts aléatoires et } \\
\text { poli par zones }\end{array}$ & $\begin{array}{c}\text { brute et } \\
\text { enlèvements }\end{array}$ & \\
\hline 10 & LCB & $1 \mathrm{a}$ & & double & ovoïde & rectangulaire & cassure & impacts et poli couvrant & $\begin{array}{c}\text { percussion } \\
\text { couvrante, violente }\end{array}$ & \\
\hline 11 & LCB & $1 \mathrm{a}$ & & double & ovoïde & semi-circulaire & cassure & impacts et poli couvrant & $\begin{array}{l}\text { percussion } \\
\text { regulière, dense } \\
\end{array}$ & \\
\hline 12 & LCB & $1 \mathrm{a}$ & & double & trapézoïdale & rectangulaire & $\begin{array}{l}\text { enlèvements } \\
\text { périphériques }\end{array}$ & impacts et poli couvrant & fine percussion & enlèvements \\
\hline 13 & Le Cadenas & $1 \mathrm{a}$ & & double & ovoïde & rectangulaire & cassure & impacts et poli couvrant & $\begin{array}{l}\text { percussion } \\
\text { régulière, dense }\end{array}$ & \\
\hline 14 & Valat & $1 \mathrm{a}$ & & double & ovoïde & semi-circulaire & $\begin{array}{l}\text { enlèvements aux } \\
\text { deux extrémités }\end{array}$ & impacts aléatoires & impacts aléatoires & enlèvements \\
\hline 15 & LCB & $1 \mathrm{a}$ & & double & triangulaire & rectangulaire & $\begin{array}{l}\text { enlèvements } \\
\text { périphériques }\end{array}$ & impacts et poli diffus & $\begin{array}{c}\text { un bord avec } \\
\text { percussion }\end{array}$ & \\
\hline 16 & LCB & $1 \mathrm{a}$ & $?$ & double & ovoïde & $\begin{array}{l}\text { semi-circulaire } \\
\text { convexe }\end{array}$ & & $\begin{array}{l}\text { impacts grossiers et } \\
\text { poli épars }\end{array}$ & impacts aléatoires & \\
\hline 17 & Rous & 1 & & & & & & & & \\
\hline 18 & PF 438 & $1 \mathrm{a}$ & & double & ovoïde & rectangulaire & $\begin{array}{l}\text { enlèvements } \\
\text { périphériques }\end{array}$ & poli? & percussion & percussion \\
\hline 19 & LCB & $1 \mathrm{a}$ & & double & trapézoïdale & rectangulaire & $?$ & $?$ & enlèvements & $?$ \\
\hline 20 & LCB & 1 & & double & semi-circulaire & rectangulaire & $?$ & $?$ & $?$ & \\
\hline 21 & LCB & 1 & $x$ & double & triangulaire & rectangulaire & & fins impacts et poli diffus & $\begin{array}{c}\text { brute et } \\
\text { enlèvements }\end{array}$ & percussion \\
\hline 22 & LCB & 1 & & double & rectangulaire & rectangulaire & & fins impacts et poli diffus & ? & $?$ \\
\hline 23 & LCB & $1 \mathrm{a}$ & & double & ovoïde & rectangulaire & & poli & $\begin{array}{l}\text { percussion } \\
\text { régulière, dense }\end{array}$ & \\
\hline 24 & LCB & $1 \mathrm{a}$ & $x$ & double & ovoïde & semi-circulaire & altération & & percussion fine? & \\
\hline 25 & LCB & $1 \mathrm{a}$ & $x$ & double & ovoïde & semi-circulaire & bords et dos bruts & poli & brute & percussion \\
\hline 26 & LCB & $1 a$ & & double & ovoïde & rectangulaire & & fins impacts et poli diffus & fine percussion & $?$ \\
\hline 27 & Valat & $1 \mathrm{a}$ & & & & & & & & \\
\hline 28 & Valat & $1 a$ & & & & & & & & \\
\hline 29 & Valat & $1 a$ & & & & & & & & \\
\hline 30 & Valat & $1 \mathrm{a}$ & & & & & & & & \\
\hline 31 & Valat & $1 \mathrm{a}$ & & & & & & & & \\
\hline 32 & Rous & 1 & & & & & & & & \\
\hline 33 & Valat & 1 & & & & & & & & \\
\hline 34 & Valat & 1 & & & & & & & & \\
\hline 35 & Valat & 1 & & & & & & & & \\
\hline 36 & ROF & 2 & & simple & quadrangulaire & quadrangulaire & $\begin{array}{c}\text { cassure } \\
\text { horizontale dos }\end{array}$ & fins impacts & brute & \\
\hline 37 & indéterminé & 2 & $x$ & simple & quadrangulaire & rectangulaire & plaquette, fracture & fins impacts & brute & percussion fine \\
\hline 38 & LCB & $1 \mathrm{a}$ & & $\begin{array}{l}\text { simple } \\
?\end{array}$ & quadrangulaire & $\begin{array}{l}\text { rectangulaire, } \\
\text { convexe }\end{array}$ & $\begin{array}{c}\text { cassure } \\
\text { horizontale dos }\end{array}$ & impacts et poli couvrant & $\begin{array}{c}\text { percussion } \\
\text { régulière, dense }\end{array}$ & \\
\hline 39 & ROF & $1 \mathrm{~b}$ & & & & & & & & \\
\hline 40 & Valat & $1 \mathrm{~b}$ & & $?$ & ovoïde & rectangulaire & & impacts et poli couvrant & $?$ & $?$ \\
\hline 41 & PF 448 & $1 \mathrm{~b}$ & & simple & ovoïde & $\begin{array}{c}\text { semi-circulaire, } \\
\text { convexe }\end{array}$ & $?$ & & $?$ & $?$ \\
\hline 42 & ROF & 2 & & & & & & & & \\
\hline 43 & ROF & 2 & & & & & & & & \\
\hline 44 & ROF & 1 & & & & & & & & \\
\hline 45 & LCB & 2 & $x$ & simple & triangulaire & semi-circulaire & cassure & fins impacts & enlèvements & brutes \\
\hline 46 & LCB & $1 \mathrm{~b}$ & & simple & trapézoïdale & rectangulaire & & fins impacts & enlèvements & \\
\hline 47 & LCB & $1 \mathrm{~b}$ & & simple & trapézoïdale & semi-circulaire & & fins impacts & brute & brutes \\
\hline 48 & LCB & $1 \mathrm{~b}$ & & simple & trapézoïdale & semi-circulaire & cassure & impacts couvrants & & percussion \\
\hline 49 & LCB & $1 \mathrm{~b}$ & & simple & quadrangulaire & rectangulaire & & impacts et poli couvrant & $\begin{array}{c}\text { brute et } \\
\text { enlèvements }\end{array}$ & \\
\hline 50 & LCB & 1 & & simple & semi-circulaire & rectangulaire & cassure, dos brut & fins impacts et poli diffus & $?$ & \\
\hline 51 & indéterminé & 1 & & & & & & & & \\
\hline 52 & Valat & $1 \mathrm{~b}$ & & simple & trapézoïdale & semi-circulaire & dos brut & impacts épars & brute & brutes \\
\hline 53 & LCB ? & $1 \mathrm{~b}$ & & simple & ovoïde & semi-circulaire & dos brut & impacts épars & brute & brutes \\
\hline 54 & LCB & 2 & & simple & rectangulaire & rectangulaire & plaquette & fins impacts & brute & percussion \\
\hline 55 & Valat & $1 \mathrm{~b}$ & & simple & triangulaire & rectangulaire & $\begin{array}{l}\text { enlèvements } \\
\text { périphériques }\end{array}$ & fins impacts et poli diffus & $\begin{array}{l}\text { fine percussion } \\
\text { par zones }\end{array}$ & percussion \\
\hline 56 & LCB & 2 & & simple & rectangulaire & rectangulaire & plaquette & fins impacts & brute & \\
\hline
\end{tabular}




\begin{tabular}{|c|c|c|c|c|c|c|c|c|c|c|}
\hline $\begin{array}{c}\mathrm{N}^{\circ} \\
\text { inv. }\end{array}$ & Site & Type & Chauffe & Cupule & Forme & Section & Techno & Face & Tranche & Extrémités \\
\hline 57 & Valat & $1 b$ & & simple & trapézoïdale & semi-circulaire & $\begin{array}{l}\text { enlèvements } \\
\text { périphériques }\end{array}$ & impacts aléatoires & enlèvements & enlèvements \\
\hline 58 & Valat & 2 & & double & trapézoïdale & semi-circulaire & & poli aspérités & $\begin{array}{l}\text { percussion } \\
\text { régulière, dense }\end{array}$ & enlèvements \\
\hline 59 & LCB & $1 b$ & & simple & ovoïde & rectangulaire & $\begin{array}{l}\text { enlèvements } \\
\text { périphériques }\end{array}$ & impacts couvrants & $\begin{array}{l}\text { fine percussion } \\
\text { par zones }\end{array}$ & \\
\hline 60 & Valat & 2 & $x$ & simple & semi-circulaire & rectangulaire & $\begin{array}{l}\text { percussion des } \\
\text { arêtes au dos }\end{array}$ & poli diffus & brute & percussion \\
\hline 61 & LCB & 1 & $?$ & simple & ovoïde & semi-circulaire & $?$ & fins impacts et poli diffus & & \\
\hline 62 & LCB & 2 & & simple & trapézoïdale & rectangulaire & dos brut & lissage et stries transversales & brute et fins impacts & enlèvements \\
\hline 63 & indéterminé & 1 & & & & & & & & \\
\hline 64 & Valat & 1 & & & & & & & & \\
\hline 65 & Valat & 1 & & simple & trapézoïdale & trapézoïdale & & $?$ & enlèvements & enlèvements \\
\hline 66 & LCB & 2 & $x$ & simple & trapézoïdale & rectangulaire & $\begin{array}{l}\text { dos brut avec poli } \\
\text { des aspérités }\end{array}$ & fins impacts et poli diffus & $\begin{array}{c}\text { brute et } \\
\text { enlèvements }\end{array}$ & \\
\hline 67 & LCB & 1 & & double & triangulaire & ovoïde & galet & brute & brute & percussion éparse \\
\hline 68 & Valat & 2 & & $\begin{array}{c}\text { simple } \\
?\end{array}$ & trapézoïdale & rectangulaire & $\begin{array}{l}\text { dos avec } \\
\text { percussion }\end{array}$ & fins impacts et poli diffus & $\begin{array}{c}\text { brute et } \\
\text { enlèvements }\end{array}$ & brutes \\
\hline 69 & LCB & 2 & $x$ & simple & trapézoïdale & rectangulaire & dos brut et poli & fins impacts et poli diffus & $\begin{array}{c}\text { brute et } \\
\text { enlèvements }\end{array}$ & \begin{tabular}{|c|} 
percussion \\
(angles percussionés)
\end{tabular} \\
\hline 70 & ROF & 2 & & & & & & & & \\
\hline 71 & indéterminé & 2 & & & & & & & & \\
\hline 72 & LCB & 2 & & & & & & & & \\
\hline 73 & LCB & 2 & $?$ & simple & triangulaire & rectangulaire & cassure & fins impacts & brute & \\
\hline 74 & Rous & 3 & & simple & circulaire & rectangulaire & dos brut et lisse & impacts et poli couvrant & percussion & \\
\hline 75 & LCB & 2 & & simple & circulaire & semi-circulaire & $\begin{array}{c}\text { brut et } \\
\text { enlèvements }\end{array}$ & lissage & $\begin{array}{l}\text { enlèvements des } \\
\text { angles }\end{array}$ & $\begin{array}{l}\text { percussion fine } \\
\text { (esquillement) }\end{array}$ \\
\hline 76 & Rous & 2 & $x$ & simple & quadrangulaire & semi-circulaire & $\begin{array}{c}\text { brut et } \\
\text { enlèvements }\end{array}$ & lissage & $\begin{array}{c}\text { enlèvements et } \\
\text { percussion }\end{array}$ & percussion d'un angle \\
\hline 77 & LCB & 2 & & simple & semi-circulaire & semi-circulaire & & fins impacts & brute & percussion? \\
\hline 78 & ROF & 3 & & & & & & & & \\
\hline 79 & Valat & 3 & & simple & ovoïde & rectangulaire & brut & brute & brute & $?$ \\
\hline 80 & LCB & 3 & & simple & ovoïde & trapézoïdale & $\begin{array}{c}\text { brut et } \\
\text { enlèvements }\end{array}$ & lissage couvrant & $\begin{array}{c}\text { zones brutes et de } \\
\text { percussion }\end{array}$ & $\begin{array}{c}\text { percussion fine } \\
\text { (deux extremités) }\end{array}$ \\
\hline 81 & PF438 & 3 & & & & & & & & \\
\hline 82 & LCB & 3 & $x$ & simple & quadrangulaire & semi-circulaire & cassure & fins impacts et poli diffus & brute & brutes \\
\hline 83 & LCB & 3 & & simple & quadrangulaire & rectangulaire & dos brut & brute & $\begin{array}{c}\text { enlèvements et } \\
\text { percussion angles }\end{array}$ & \\
\hline 84 & LCB & 3 & $x$ & simple & quadrangulaire & triangulaire & cassure & $\begin{array}{l}\text { impacts aléatoires, } \\
\text { poli autour cupule }\end{array}$ & brute & brutes \\
\hline 85 & Pitrous & 3 & & simple & trapézoïdale & trapézoïdale & cassure & & $\begin{array}{l}\text { pans bruts et } \\
\text { enlèvements }\end{array}$ & percussion \\
\hline 86 & ROF & 4 & & & & & & & & \\
\hline 87 & ROF & 4 & & & & & & & & \\
\hline 88 & ROF & 4 & & & & & & & & \\
\hline 89 & indéterminé & 4 & $x$ & & & & & & & \\
\hline 90 & LCB & 4 & & & & & & & & \\
\hline 91 & LCB & 3 & & & & & & & & \\
\hline 92 & LCB & 4 & $x$ & double & rectangulaire & triangulaire & & fins impacts et poli diffus & brute et polie & percussion, fortement \\
\hline 93 & Valat & 1 & & & & & & & & \\
\hline 94 & Valat & 1 & & & & & & & & \\
\hline 95 & Valat & 1 & & & & & & & & \\
\hline 96 & Valat & 1 & & & & & & & & \\
\hline 97 & Valat & 1 & & & & & & & & \\
\hline 98 & Valat & 1 & & & & & & & & \\
\hline 99 & Valat & 1 & & & & & & & & \\
\hline 100 & Valat & 1 & & & & & & & & \\
\hline 101 & Valat & 1 & & & & & & & & \\
\hline 102 & Valat & 1 & & & & & & & & \\
\hline 103 & Valat & 1 & & & & & & & & \\
\hline 104 & ROF & indéterminé & & & & & & & & \\
\hline 105 & ROF & indéterminé & & & & & & & & \\
\hline 106 & ROF & indéterminé & & & & & & & & \\
\hline 107 & ROF & indéterminé & & & & & & & & \\
\hline 108 & ROF & indéterminé & & & & & & & & \\
\hline 109 & ROF & indéterminé & & & & & & & & \\
\hline 110 & ROF & indéterminé & & & & & & & & \\
\hline 111 & ROF & indéterminé & & & & & & & & \\
\hline 112 & ROF & indéterminé & & & & & & & & \\
\hline 113 & ROF & indéterminé & & & & & & & & \\
\hline 114 & ROF & indéterminé & & & & & & & & \\
\hline 115 & LCB & 1 & & & & & & & & \\
\hline 116 & LCB & 2 & $x$ & simple & rectangulaire & rectangulaire & cassure & & brute & \\
\hline
\end{tabular}




\title{
BIBLIOGRAPHIE
}

\author{
AbRÉViations \\ APDCA Association pour la promotion et la diffusion des connaissances archéologiques. \\ BAR British Archaeological Report. \\ BRGM Bureau de recherches géologiques et minières. \\ BSPF Bulletin de la Société préhistorique française. \\ CTHS Comité des travaux historiques et scientifiques. \\ DAF Documents d'archéologie française. \\ EFR École française de Rome. \\ MSH Maison des sciences de l'homme. \\ SPF Société préhistorique française.
}

Alimov K. VON, BOROFFKA N., Bubnova M., BurJakov J., Cierny J., Jabukov J., Lutz J., Parzinger H., PERNICKA E., RADIlilovSKIJ V., RUZANo V., Sirinov T., STARSinin D., WEISGERBER G.

1998: «Prähistorischer Zinnbergbau in Mittelasien, Kampagne 1997 », Eurasia Antiqua, Zeitschrift für Archaologie Eurasiens, 4, p. $137-199$.

AMbert P.

1992: «L'émergence de la métallurgie en France méridionale: état actuel des connaissances», in "Actes du colloque en hommage à J. Arnal, Saint-Mathieu de Tréviers", Archéologie en Languedoc, 15 , 1990-1991, p. 51-58.

1995: «Les mines préhistoriques de Cabrières (Hérault) : quinze ans de recherches, état de la question », BSPF, 92, 4, p. 499-508.

1997: «Recherches sur les fours de métallurgistes chalcolithiques et de l'âge du Bronze d'Europe occidentale (domaines méditerranéens et alpins): état de la question, perspectives de recherches", Archéologie en Languedoc, 21, p. 29-49.

AMbert P., BARge H., BoURhiS J.-R., ESPÉROU J.-L.

1984: «Mines de cuivre préhistoriques de Cabrières (Hérault) : premiers résultats ", $B S P F, 81,3$, p. 83-89.

1985: «Mise en évidence, âge et niveau technique des exploitations préhistoriques cuprifères de Cabrières (Hérault) ", Archéologie en Languedoc, 4, p. 91-95.

AMBERT P., BOUQUeT L., GUENDON J.-L., MISCHKA D.

2005: «La Capitelle du Broum (district minier de Cabrières-Péret, Hérault) établissement industriel de l'aurore de la métallurgie française (3100-2400 B.C.) ", in AMBERT P., VAQUER J. (DIR.), La Première métallurgie en France et dans les pays limitrophes, Actes du colloque international de Carcassonne, 28-30 sept. 2002, Paris, SPF (coll. Mémoire de la SPF, XXXVII), p. $83-96$.

ambert P., Coularou J., Cert C., GUENDON J.-L., Bourgarit D., Mille B., Dainat D., Houlès N., BEAUMES B.

2002: «Le plus vieil établissement de métallurgistes de France (3100-2880 cal. BC), Péret, Hérault», Compte rendu Palevol (Académie des Sciences, Paléo-environnement), 1,1 , p. $67-74$

Ambert P., Goularou J., Guendon J.-L.

2003: «État des recherches concernant le village chalcolithique de métallurgistes de la Capitelle du Broum à Péret, Hérault, France", in FERNANDEZ MANZANO J., HERRAN MARTINEZ J. (DIR.), Mineros y fundidores en el inicio de la edad de los metales, Madrid, Fundación Las Médulas, León, p. 49-58.

AMberT P., LAROche M., GUENDON J.-L., Figueroa-Larre V., OberWeiler C., BOLZ V., ROVIRA S.

2006: Mines et métallurgies préhistoriques des cuivres à antimoine-argent du Midi de la France (Languedoc-Rousillon), Projet collectif de recherche, Rapport d'activités auprès du ministère de la Culture et de la Communication, 62 p., 27 fig.

\section{Aubague M., Orgeval J.-J., Soulier M.}

1977: "Les gîtes minéraux de la terminaison méridionale du Massif central et de sa bordure languedocienne (essai de synthèse) ", Bulletin du BRGM, section II, n 3, p. 139-181.

Barge H., ANCEl B., Rostan P., GUENDON J.-L.

1998: «La mine des Clausis à Saint-Véran (Hautes-Alpes): exploitation et aire de réduction du minerai de cuivre d'époque préhistorique", in MORDANT C., PERNOT M., RYCHNER V. (DIR.), L'Atelier $d u$ bronzier en Europe, Actes du colloque Bronze' 96, Neuchâtel et Dijon - 2-Du minerai au métal, du métal à l’objet, Paris, CTHS (coll. Documents préhistoriques, 10), p. 71-82.

BARGE H., BOURHIS J.-R. AVEC LA PARTICIPATION DE ROSTAN P.

1998: «Métallurgie préhistorique et gîtes cuprifères dans le sud-est de la France: premiers résultats", in D'ANNA A., BINDER D. (DIR.), Production et identité culturelle, Actes des $2^{e}$ rencontres méridionales de Préhistoire récente, Arles, 1996, Antibes, APDCA p. 65-79.

BARTHELEim M., ECKSTEIN K. huijmans M., Kraub R., Pernicka E.

2003: "Chalcolithic metal extraction in Brixlegg, Austria», in Archeometallurgy in Europe, International Conference, Milano, Associacione italiana di Metallurgia, vol. 1, p. 441-447.

BEAUNE S. DE

1989: «Essai d'une classification typologique des galets et plaquettes utilisés au Paléolithique», Gallia Préhistoire, 31, p. 27-64.

2000: Pour une archéologie du geste: broyer, moudre, piler. Des premiers chasseurs aux 
premiers agriculteurs, Paris, CNRS Éditions, $231 \mathrm{p}$.

Becker A., TOUSSAint M., LAWARréE G.

1994: «Galets à cupules et galets perforés du Mésolithique mosan", Bulletin des chercheurs de la Wallonie, XXXIV, p. 5-26.

\section{Blas Cortina M. A. DE}

2005: «Un témoignage probant de l'exploitation préhistorique du cuivre dans le nord de la péninsule Ibérique: le complexe minier d'El Aramo (Asturies)", in AMbert P., VAQUER J. (DIR.), La Première métallurgie en France et dans les pays limitrophes, Actes du colloque international de Carcassonne, 28-30 sept. 2002, Paris, SPF (coll. Mémoire de la SPF, XXXVII), p. 195-205.

BOUQUET L., FIGUEROA-LARRE V., LAROCHE M., GUENDON J.-L., AMbert P.

2006: «Les Neuf-Bouches (district minier de Cabrières-Péret), la plus ancienne exploitation minière de cuivre de France: travaux récents, conséquences", $B S P F$, 103 1, p. 143-159.

BUTLER J. J., VAN DER WAALS J. D.

1966: «Bell beakers and early metal-working in the Netherlands ", Palaeohistoria, XII, p. 42-139.

Capitani A. De, Deschler-Erb S., LEUZinger U., MARTi-Gradel E., SCHIBLER J.

2002: Die jungsteinzeitliche Seeufersiedlung Arbon/Bleiche 3 Funde, Departement fur Erziehung und Kultur des Kantons Thurgau, p. 59-62.

\section{Cert C.}

2003: «Les outils de métallurgistes de la Capitelle du Broum à Péret (Hérault) : données préliminaires dans le contexte régional», in FERNANDEZ MANZANO J., HERRAN MARTINEZ J. (DIR.), Mineros y fundidores en el inicio de la edad de los metales, Madrid, Fundación Las Médulas, León, p. 59-69.

2005: «Les outils de métallurgiste du site du Néolithique final de la Capitelle du Broum (Péret, Hérault) ", in AMBERT P., VAQUER J. (DIR.), La Première métallurgie en France et dans les pays limitrophes, Actes du colloque international de Carcassonne, 28-30 sept. 2002, Paris, SPF (coll. Mémoire de la SPF, XXXVII), p. 109-115.

Colomer A., Coularou J., Gutherz X. 1990 : Boussargues (Argelliers-Hérault), un habitat ceinturé chalcolithique: le secteur ouest, Paris, MSH (coll. DAF, 24), 220 p.

\section{Domergue C.}

1990: Les Mines de la péninsule Ibérique dans l'Antiquité romaine, Rome, EFR (coll. EFR, 127), 327 p.

\section{DOMINGEZ S.}

2001: «Utiles mineros en la Prehistoria del Sudeste de Extremadura: analisis petrologico, geoquimica y determinacion de las areas fuente de las materias primas ", in GÓMEZ TUBÍO B., Respaldiza Galisteo M. A., PARdo RODRÍGUEZ M. L. (DIR.), Actas del III congreso nacional de Arqueometría, Sevilla, dic. de 1999, Sevilla, Universidad de Sevilla, p. 611-620.

\section{ESPÉROU J.-L.}

1988: «Un outil de métallurgiste aux fonctions imprécises », BSPF, 85, 2, p. 37-38.

1993: «La structure métallurgique chalcolithique de Roque-Fenestre (Cabrières, Hérault)", Archéologie en Languedoc, 17, p. 32-46.

2006: Cadenas/Valat-Grand, Cabrières (Hérault), Rapport final d'opération, Diagnostic archéologique, Inrap, $\mathrm{n}^{\circ}$ d'opération: 2005/284, 49 p., 51 fig.

ESPÉROU J.-L., AMBERT P., BOURHIS J.-R., RoQUes P., Gilot E., CHABal L.

1994: «La fosse chalcolithique de Pioch Farrus 448 », Bulletin du Musée d'Anthropologie préhistorique de Monaco, 37, p. 53-62.

\section{ESPÉroU J.-L., RoQUes P., AMBERT P.}

1992: «L'outillage des mineurs préhistoriques de Cabrières: les broyeurs", in "Actes du colloque en hommage à J. Arnal, Saint-Mathieu de Tréviers ", Archéologie en Languedoc, 15, 1990-1991, p. 67-76.

Guendon J.-L., Salazar D., FigueroaLARre V., SAlinas H., LAROche M., AMbert P., GRUNeisen A.

2008: Les Mines de cuivre du Néolithique final du district de Cabrières-Péret (Hérault, France): le point sur les dernières recherches, les haldes minières du plateau de Bellarade, Pré-actes des $8^{e}$ rencontres méridionales de Préhistoire récente, Marseille 7-8 nov. 2008, p. 62.

\section{HAMON C.}

2006a: Broyage et abrasion au Néolithique ancien : caractérisation technique et fonctionnelle des outillages en grès du Bassin parisien, Oxford, Archaeopress (coll. BAR, International Series, 1551), 342 p. 2006b: «Fonction et usage des galets à cupules $\mathrm{du}$ site chalcolithique de la Capitelle du Broum à Péret (Hérault) », CU+, Bulletin du Groupe de travail international sur la paléométallurgie du cuivre, 5, p. 17-20.

\section{HUNT M.}

2003: Prehistoric Mining and Metallurgy in the Southwest Iberian Peninsula, Oxford, Archaeopress (coll. BAR, International Series, 1188), p. 292-293.

\section{LAROCHE M.}

2004: Productions métallurgiques protohistoriques sensu lato (III ${ }^{e} I^{e r}$ millénaire av. J.-C.) dans les monts de Cabrières, de Saint-Guilhem et du Lodévois, DEA., EHESS, Toulouse, 207 p.

\section{O'BRIEN W.}

2004: Ross Island: mining, metal and society in Early Ireland, Galway, National University of Ireland (coll. Bronze Age Studies, 6), 768 p.

PICKIN J.

1990: Stone tools and early metal mining in England and Wales: early mining in the British Iles, Park National of Snowdon, Crew ed., Paper 1, p. 39-42.

\section{PREUSCHEN E.}

1973: «Estrazione mineraria dell'eta del bronzo nel Trentino", Preistoria alpina, 9, p. $113-150$

\section{RAHIR E.}

1925: «La station Leduc (époque tardenoisienne) à Remouchamps?", Bulletin de la Société d'anthropologie de Bruxelles, 40, p. $90-101$.

\section{REISER B., SGHRATTENTHALER H.}

1998-1999: «Urgeschichtlicher Kupferbergbau im Rauim SchwazBrixlegg, Tirol», Archaeologia austarica, 82-83, p. 135-177.

Saez R., Nocete F., Camalich M. D.

2004: «La captacion de materias primas para la metalurgia » in NOCETE F. (DIR.), Odiel: proyecto de investigacion para el analisis del origen de la desigualdad social en el Suroeste de la Peninsula Iberica, Sevilla, Junta de Andalucia, Consejeria de Cultura (coll. Monografias de arqueologia, 19), p. 265-271.

\section{SIMON J. L.}

1998: La Metalurgia Prehistorica Valenciana, Valence, Servicio de Investigacion Prehistorica (coll. Trabajos Varios, 93). 
Simon J. L., Hernandez S., GIL F.

1999: La Metalurgia en el Altiplano de JumillaYecla: Prehistoria y Protohistoria, Murcia, Caja de Ahorros del Mediterraneo.

SIRET L.

1887: Les Premiers âges du métal dans le sud-est de l'Espagne, Bruxelles.

\section{STRAHM C.}

1994: «Die Anfänge der Mettalurgie in Mitteleuropa", Helvetia archaeologia, 25, p. 2-39.

2005: «L'introduction et la diffusion de la métallurgie en France", in AMBERT P., VAQUER J. (DIR.), La Première métallurgie en France et dans les pays limitrophes, Actes du colloque international de Carcassonne, 28-30 sept. 2002, Paris, SPF (coll. Mémoire de la SPF, XXXVII), p. 27-36.

\section{TCHEREMISSINOFF Y. (DIR.)}

2006: "La Vayssonnié» et «La Salaberdié» : deux occupations domestiques de l'âge du Cuivre dans le Ségala (Tarn, France), Castres, Comité départemental d'archéologie du Tarn, (coll. Monographie d'archéologie tarnaise, 1), 343 p.

WAgner G. A., Oztunal $O$.

2000: «Prehistoric copper sources in Turkey,
Anatolian Metal I», Der Anschnitt, Zeitschrift für Kunst und Kultur im Bergbau, 13, Veröffentlichungen aus dem Deutschen Bergbau-Museum, 92 p. 47.

\section{WEISGERBER G.}

1982: "Towards a history of copper mining in Cyprus and the Near East: possibilities of mining archaeology", in MUHLY J. D., MADDIN R., KARAGEORGHIS V. (DIR.), Early Metallurgy in Cyprus, 4000-500 B.C., Acta of the International Archaeological Symposium, Larnaca, Cyprus Pierides Foundation and Dept. of Antiquities, 1-6 june 1981, Nicosie, Stavrinides, p. 25-32. 